\title{
Erbium(III) Coordination at the Surface of an
}

\section{Aqueous Electrolyte}

Mrinal K. Bera, ${ }^{\dagger}$ Guangming Luo, ${ }^{\dagger, \alpha}$ Mark L. Schlossman, ${ }^{\ddagger, *}$ L. Soderholm, ${ }^{\dagger, *}$ Sungsik Lee, ${ }^{\S}$ and Mark R. Antonio ${ }^{\dagger, *}$

${ }^{\dagger}$ Chemical Sciences \& Engineering Division, and ${ }^{\S}$ Advanced Photon Source X-ray Science Division, Argonne National Laboratory, Argonne, Illinois 60439, United States

Department of Physics, University of Illinois at Chicago, Chicago, Illinois 60607, United States

KEYWORDS. Surface chemistry, Electrolytes, X-ray absorption spectroscopy, Rare Earths, Interfaces

ABSTRACT. Grazing-incidence (GI) X-ray absorption spectroscopy (XAS) under conditions of total external reflection is used to explore the coordination environment of the trivalent erbium ion, $\mathrm{Er}^{3+}$, at an electrolyte-vapor interface. A parallel study of the bulk aqueous electrolyte (1 M $\mathrm{ErCl}_{3}$ in $\mathrm{HCl}$ at $\mathrm{pH}=1.54$ ) shows that the $\mathrm{Er}^{3+}$ ions have a simple hydration shell with an average Er- $-\mathrm{OH}_{2}$ bond distance of 2.33(1) $\AA$, consistent with previous descriptions of the aquated cation, $\left[\operatorname{Er}\left(\mathrm{OH}_{2}\right)_{8}\right]^{3+}$. No other correlations are observed in the electrolyte EXAFS (extended X-ray absorption fine structure) data acquired at room temperature. In contrast, the coordination of the $\mathrm{Er}^{3+}$ ions at the electrolyte-helium interface - as interrogated by use of electron-yield detection- 
reveal correlations beyond the $\mathrm{Er}-\mathrm{OH}_{2}$ hydration shell that are unexpectedly well-defined. Analyses show an environment that consists of a first coordination sphere of 6-7 $\mathrm{O}$ atoms at 2.36(1) $\AA$ and a second one of $3 \mathrm{Cl}$ atoms at 2.89(2) $\AA$, suggesting the formation of a neutral $\left[\left(\mathrm{H}_{2} \mathrm{O}\right)_{6-7} \mathrm{ErCl}_{3}\right]$ entity at the surface of the electrolyte. The presence of a third, distant peak in the Fourier transform data is attributed to Er-Er correlations (in possible combination with contributions from distant $\mathrm{Er}-\mathrm{O}$ and $\mathrm{Er}-\mathrm{Cl}$ interactions). The best- $\mathrm{Z}$ and -integer fits reveal $3 \mathrm{Er}$

atoms at 3.20(2) Å, confirming the near-surface-enrichment of $\mathrm{Er}^{3+}$ as revealed previously by use of X-ray reflectivity measurements (J. Phys. Chem. C 2013, 117, 19082). Here, the strong associations between the Er-aqua-chloro entities at the electrolyte-vapor interface are shown to be consistent with the formation of domains of polynuclear cluster motifs, such as would arise through hydrolysis reactions of the aquated $\mathrm{Er}^{3+}$ cations. The local structural results and the calculated surface coverage are of relevance to understand the myriad reactions involved in the hydrometallurgical process of solvent extraction (SX) for metal purification, which involves the transfer of a selected metal ion, like Er, across an interface from an aqueous electrolyte to an organic phase

\section{INTRODUCTION}

The coordination chemistry of metal ions in aqueous electrolyte solutions plays a critical role in their reactivity, stability, solubility, and transport. Predicting these behaviors is complicated by difficulties in obtaining metrical information with the precision necessary to develop an understanding of the interatomic-level processes at play and their relative importance. Despite long-standing experimental and theoretical interests, there is no generally-agreed structural model for bulk liquid electrolytes ${ }^{1,2}$ let alone for their interfaces, ${ }^{3}$ for which it is becoming 
increasingly evident that the distribution of solutes are far from homogeneous and, in fact, exhibit correlations on length scales from atom-to-molecule-to-cluster. ${ }^{4-12}$ In an atomistic view of an electrolyte solution, there are myriad correlations (i.e., solute-solvent, solute-solute, solventsolvent) involving ion-ion, ion-dipole, and dipole-dipole interactions. Much of the recent experimental effort to provide details about metal ion coordination chemistry in electrolytes, including the identity and number of coordinating ligands as well as the metal-ligand distances, has utilized X-ray absorption fine structure (XAFS) as a tool of choice. ${ }^{13-15}$ A single-ion probe, XAFS provides a simplifying cut through the swath of all possible pair distributions in the electrolyte; only correlations involving the selected metal are probed, thereby providing a metalion-centric perspective on its environment out to distances of approximately $5 \AA$ with a precision of approximately $\pm 0.01 \AA$ on the metal-ligand distance and about $\pm 10 \%$ on the coordination number. ${ }^{16-18}$ In the absence of interfering ions, this can be done to sub-millimolar concentrations for complex solutions under optimal conditions. Recently, high-energy X-ray scattering (HEXS) has been proven to provide complementary information, notably improving the precision of the coordination number to about $\pm 2 \%$ and extending the region probed to $10 \AA$ or more under favorable conditions. ${ }^{19-22}$ This is done at the expense of single-ion sensitivity and metal-ligand distance precision for high (e.g., molar) concentrations of electrolytes.

Our specific interest in metal ion speciation of electrolyte solutions includes the development of a predictive understanding of solvent extraction (SX) processes for rare-earth-element separations. ${ }^{23}$ Since the report of the first kilogram-scale production of gadolinium oxide in $1953,{ }^{24} \mathrm{SX}$ chemistry is the benchmark technology for the commercial separation and purification of rare earths, which are of contemporary technological interest as catalysts, ${ }^{25}$ superconductors,${ }^{26,27}$ molecular magnets,${ }^{28}$ and phosphors ${ }^{29}$ Because SX relies on very small 
changes in metal-ion free energies between the aqueous and organic phases to drive the phase transfer of the targeted species across the interface, it is a very difficult process to model, requiring comparative energetics reliable to $2 k_{B} T$. With the goal of improving current understanding of a dissolved metal's inner- and outer-sphere correlations, we recently performed HEXS experiments on erbium $(\mathrm{Z}=68)$ in acidic, aqueous chloride electrolytes ${ }^{30} \mathrm{Er}$ was chosen because it is a small and electrochemically inactive trivalent rare-earth ion with a well-defined coordination environment in solution. ${ }^{31}$ HEXS data confirmed previous experimental reports that $\mathrm{Er}^{3+}$ has eight waters in its first coordination shell in aqueous solution at low chloride ion concentration. The results also found that, as the chloride ion concentration is increased, it coordinates as both an inner and outer sphere ligand. These results provide insight into the molecular level details of species associated with previously reported thermodynamic stability constants for $\mathrm{Er}-\mathrm{Cl}$ complexes in bulk solution. ${ }^{32} \mathrm{In}$ an independent study of bulk $\mathrm{ErCl}_{3}$ aqueous solutions using X-ray diffraction, ${ }^{33}$ cation-anion ordering was shown to be concentrationdependent; specifically, pseudo-crystalline structures were found at high concentrations and, in dilute solutions, solvent-like structures with long range order were observed.

Although an important first step, the bulk coordination of Er in the aqueous phase represents only one aspect of the overall energetics that influence its SX. Also important is speciation at the liquid-liquid interface, where the phase transfer occurs. Initial experiments to address interfacial adsorption were undertaken using X-ray fluorescence to probe the Er concentration at the liquidliquid boundary between an organic solvent ( $n$-dodecane) and an acidic $\mathrm{ErCl}_{3}$ aqueous electrolyte ${ }^{34}$ The results showed an upper limit for the Er concentration at the interface that was consistent with a uniform concentration extending from the bulk to the surface. Complementary X-ray reflectivity experiments, which provided sub-nanometer spatial resolution along the 
direction perpendicular to the aqueous $\mathrm{ErCl}_{3}$ electrolyte-vapor surface, showed a non-monotonic variation of Er concentration in this direction - with a depletion layer at the surface followed by a subsurface enhancement layer ${ }^{35}$ - a finding contrary to our initial assumption from a separations perspective but consistent with known negative adsorption behaviors of multivalent cations at an interface..$^{10,36-42}$ Both surface depletion and subsurface enrichment of $\mathrm{Er}^{3+}$ lead to local variations in concentration that can induce different interion orderings in much the same manner as found in bulk electrolytes of different concentrations. ${ }^{33}$ In an effort to extend our understanding of the molecular-level speciation of Er at and near the electrolyte-vapor interface, we conducted XAFS (X-ray absorption fine structure) experiments that included a comparison of the bulk speciation using fluorescence detection with that at the surface using electron-yield detection under conditions of total external reflection (i.e., grazing incidence). We describe herein details of the electron-yield experiments together with the results of these measurements. Although the bulk measurements are in agreement with those obtained previously from XAFS ${ }^{43-}$ ${ }^{46}$ and X-ray scattering that show a simple aquated cation,,$^{30,31,47,48}$ the electron-yield response provides evidence of significant $\mathrm{Er}-\mathrm{Cl}$ and Er-Er correlations within approx. $30 \AA$ of the electrolyte surface. This result, while unexpected, fits together well with the non-monotonic $\mathrm{Er}^{3+}$ distribution and oscillatory intrinsic electron density profile, $\varrho_{\text {int }}(z)$, into the same depth of the electrolyte. ${ }^{35}$ Although the results presented here are for an aqueous-air interface, the system properties are comparable to aqueous-organic interfaces in that the dielectric constants of paraffinic organic phases $(\sim 2)$ are essentially equivalent to that for air $(\sim 1)$, and both are much smaller than those $(\sim 78)$ for the aqueous phases.

\section{EXPERIMENTAL METHODS}


Ultra-high-purity water (18.2 M $\Omega$-cm and 2 ppb TOC from a Barnstead Nanopure water system) and hydrochloric acid (Fisher Chemical Optima grade) were used to prepare an aqueous electrolyte of $\mathrm{pH}=2.0$. A pink solution of $1.0 \mathrm{M} \mathrm{ErCl}_{3}$ was obtained from the dissolution of erbium chloride hexahydrate (Alfa Aesar, purity 99.99\%) in the prepared $\mathrm{pH}=2$ aqueous electrolyte. The solution was then filtered through a 0.2 micron Omnipore PTFE membrane into a PTFE container. The $\mathrm{pH}$ and density of the final $1.0 \mathrm{M} \mathrm{ErCl}_{3}$ solution were measured as 1.54 and $1.252 \pm 0.005 \mathrm{~g} \mathrm{~cm}^{-3}$, respectively.

Erbium $\mathrm{L}_{3}$-edge $(8,358 \mathrm{eV}) \mathrm{X}$-ray absorption data were acquired at room temperature on bending magnet station 12-BM-B at the Advanced Photon Source (Argonne National Laboratory) with a $\mathrm{Rh}$ focusing mirror and $\mathrm{Si}<111>$ monochromator. ${ }^{49}$ The energy bandwidth afforded by the beam line configuration was estimated to be $1 \mathrm{eV}$ at the $\mathrm{L}_{3}$-edge energy, providing an instrumental resolution that is more than $4 \times$ smaller than the natural linewidth of $4.35 \mathrm{eV}$ for the $\mathrm{Er} \mathrm{L}_{3}$ core hole. ${ }^{50}$ Hence, the Er $\mathrm{L}_{3}$-edge XANES obtained here are negligibly broadened $(\leq 3 \%)$ by the instrumental resolution function. The incident X-ray energy was calibrated using Ni foil (EXAFS Materials ${ }^{51}$ ) by setting the inflection point in the first differential XANES (X-ray absorption near edge structure) to $8,333 \mathrm{eV}$. The $1.0 \mathrm{M} \mathrm{ErCl}_{3}$ solution electrolyte was contained in a commercial NIMA Langmuir trough (KSV-NIMA Company), with surface area $30 \mathrm{~cm} \times 10 \mathrm{~cm}$, enclosed in purpose-built enclosure that was purged with helium for the surface measurements at grazing incidence. A $1 \mathrm{~mL}$ aliquot of the same electrolyte was contained in a SPEX micro X-cell (No. 3577) for bulk measurement at normal incidence with fluorescence detection, and surface measurements of solid powders of $\mathrm{ErCl}_{3} \cdot 6 \mathrm{H}_{2} \mathrm{O}$ and $\mathrm{Er}_{2} \mathrm{O}_{3}$ (Alfa Aesar, No. 11309) were obtained with electron-yield detection in the conventional $45 / 45^{\circ}$ configuration. A slit of $500 \mu \mathrm{m} \times 50 \mu \mathrm{m}$ (horizontal $\mathrm{x}$ vertical) was used before the liquid and solid samples. The incident beam was 
reflected off the electrolyte surface at a fixed angle of $0.68 \mathrm{mrad}$. At this incident angle, conditions of total external X-ray reflection are maintained at all energies $(8.2-8.9 \mathrm{keV})$ throughout the scan (see Supporting Information, Fig. 1). The total footprint of the beam on the solution surface along the beam direction was about $7.3 \mathrm{~cm}$ long, traversing most of the surface area across the trough in the beam direction. In the electron orbital plane, the bending magnet radiation is linearly polarized. Because the liquid surface is oriented in parallel with the orbital plane, there are possibilities for X-ray linear dichroism effects in the X-ray absorption spectra, such as seen beforehand for transition-metal complexes at the water-air interface ${ }^{52-57}$ Out of the electron orbital plane, the bending magnet radiation has some degree of left/right circular polarization. The alignment was continuously monitored throughout the ca. 36 hours of scanupon-scan data collection by measurements and observations of the totally-reflected beam intensity and position with a phosphor screen with digital camera. Surface tensions measurements made at the start and at the conclusion of the X-ray absorption experiments are identical to those reported beforehand ${ }^{35}$ the results are diagnostic of a pure and clean electrolyte-He interface. 


\section{Top View}

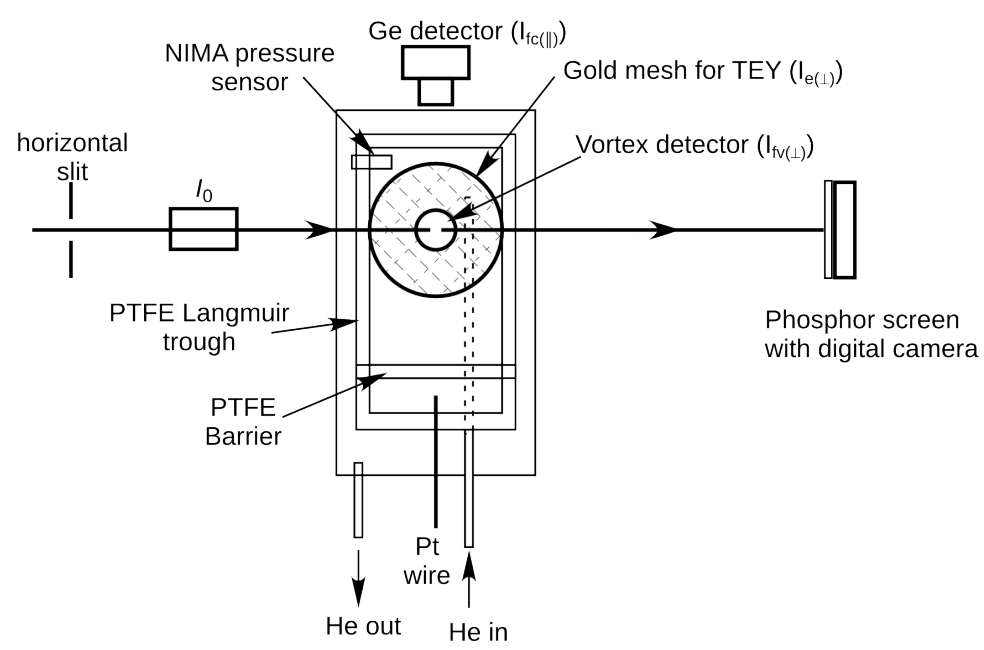

\section{Side View}

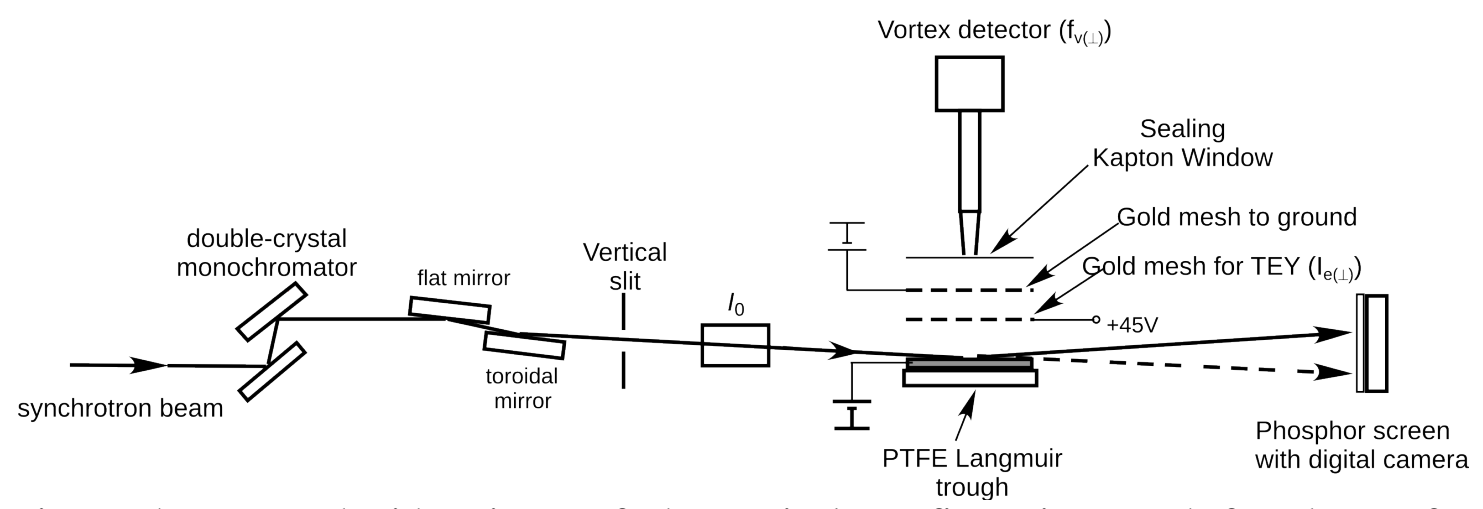

Figure 1 Top and side views of the optical configuration used for the surface-EXAFS measurements at grazing incidence.

The configuration of the X-ray optics, the enclosed trough, and detector geometries are

illustrated in Figure 1. A circular piece of gold mesh (Precision Eforming, 30 lines-per-inch,

Item code MG8) with a diameter of $10 \mathrm{~cm}$ and $90 \%$ transparency was used to collect the emitted electrons at $1 \mathrm{~cm}$ above the electrolyte surface with a $+45 \mathrm{~V}$ biased potential obtained with two $22 \frac{1}{2} \mathrm{~V}$ batteries (Eveready No. 412). Another $90 \%$ transparency gold mesh with same electric potential as the water surface was placed before the Kapton window (7.5 $\mu \mathrm{M}$ thick, Chemplex Industries, No. 440) enclosure seal to avoid charge accumulation on the electrolyte surface. The total electron yield signal (denoted $\mathrm{I}_{\mathrm{e}(\perp)}$ ) from the solution surface was obtained with the 
aforementioned locally engineered detector (which was aligned perpendicular to the incoming Xray beam and perpendicular to the electrolyte surface) of the design illustrated in Figure 2.

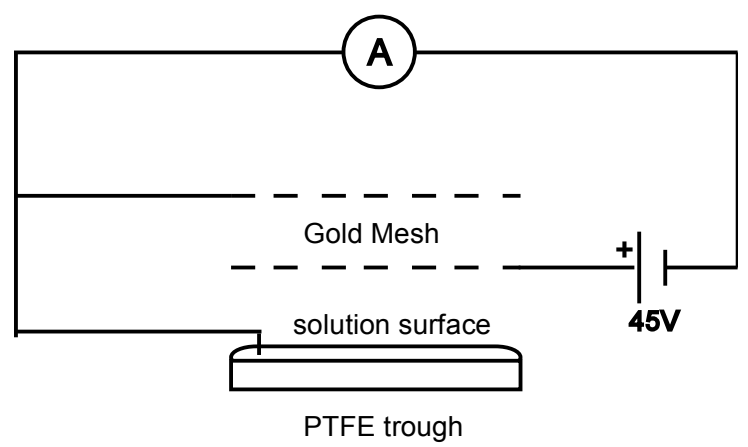

Figure 2 Simplified circuit diagram for total-electron yield data collection from a liquid surface at the grazing incidence conditions of Figure 1. Current amplification (A) was achieved with a SRS Model SR570 preamplifier.

The Er $\mathrm{L}_{\alpha}$ fluorescence signal was collected with two different detectors: (1) a 13-element Ge detector (Canberra) aligned perpendicular to the incoming X-ray beam and parallel to the electrolyte surface, denoted $\mathrm{I}_{\mathrm{fc}(\mathrm{II}}$, and; (2) a 4-element Si detector (Vortex ME-4) aligned perpendicular to the incoming X-ray beam and perpendicular to the electrolyte surface, denoted $I_{\mathrm{fv}(\perp)}$. To measure the fluorescence signal from the flat solution surface area, a $10 \mathrm{~cm}$ long silver foil (Goodfellow, $0.125 \mathrm{~mm}$ thick, Cat. No. AG000400) snout with a $2 \mathrm{~cm}$ open aperture along the beam direction was used before the Vortex ME-4 detector; the end of the snout was located about $3 \mathrm{~cm}$ above the water surface. A similar Ag snout was used before Ge detector; the end of this snout was located $15 \mathrm{~cm}$ from and orthogonal to the horizontal beam. The reflected beam on the phosphor screen with digital camera and fluorescence signal measured by the Vortex ME-4 detector were used to align the beam footprint at the center of the electrolyte solution surface, by 
moving the sample table vertically with a step resolution of about $6 \mu \mathrm{m}$, corresponding to a horizontal motion of about $0.9 \mathrm{~cm}$ of the beam footprint along the solution surface.

The 1/e penetration depth of the evanescent wave produced by the incident X-ray photons (8.2$8.9 \mathrm{keV}$ ) at the glancing angle of $0.68 \mathrm{mrad}$ is calculated to be $45 \AA$ (see Supporting Information, Fig. 2). The 1/e penetration depth of Er L $\alpha$ fluorescence photons (ca. $6.9 \mathrm{keV}$ ) is estimated to be $300 \mu \mathrm{m}$. Its response, much like the one of our previous design,$^{58}$ is vitiated by the presence of oxygen, and the best data are acquired with a pure helium atmosphere containing less than $4 \%$ $\mathrm{O}_{2}$ - as measured by the oxygen sensor (City Technology, AO2 Oxygen sensor PTB-18.10) that provides secondary electron-signal amplification.$^{59-62}$ The 1/e attenuation length of the emitted electrons, largely dominated by Er LMM Auger processes $(E \approx 5.7 \mathrm{keV}$ as extrapolated from published data, ${ }^{63}$ see Supplementary Information Fig. 3), is estimated to be $106 \AA$ A. Under conditions of total reflection, such as obtained here, the effective probing depth of the Auger electrons in pure water is reduced by approximately threefold to ca. $31 \AA^{64}$ (refer to the Supporting Information for details). Although there is no empirical way of calculating the probing depth of electrons in an electrolyte solution, it would not be unrealistic to assume that the effective probing depth would be less than that of pure water. In particular, when the $\mathrm{Er}^{3+}$ ion concentration near the surface is higher than that of the bulk (as evidenced from earlier experiments), ${ }^{35}$ the probing depth will be much smaller than $31 \AA$ A. As such, the electron-yield signal is more sensitive to the surface ion distribution than the X-ray fluorescence signal, which arises from an ion distribution some 1.5 times deeper ( $45 \AA)$ into the bulk solution in the path of the reflected X-rays. Nonetheless, both X-ray fluorescence and electron-yield signals were weak, requiring the acquisition and averaging of multiple scans, whereas the bulk solution data were acquired in a single scan. The averaged and normalized surface-sensitive responses, in terms of 
$\mathrm{I}_{\mathrm{e}(\perp)}, \mathrm{I}_{\mathrm{fc}(\mathrm{II})}$, and $\mathrm{I}_{\mathrm{fv}(\perp)}$ vs. energy, $\mathrm{keV}$, are provided as Supporting Information (Fig. 4) along with the bulk electrolyte response measured by fluorescence, $\mathrm{I}_{\mathrm{f}(\mathrm{bulk})}$ in the conventional $45 / 45^{\circ}$ geometry, for comparison. The data in the XANES region were acquired at $0.4 \mathrm{eV}$ per point, between 8.3379 and $8.3879 \mathrm{keV}$, for the purpose of XANES-fitting with WinXAS ${ }^{65}$ The EXAFS data were sampled at steps of $0.04 \AA^{-1}$. All data processing and analyses were performed in identical fashion by use of EXAFSPAK and with single-scattering $\mathrm{O}, \mathrm{Cl}$, and Er amplitudes and phases $\left(F_{\mathrm{j}}(k)\right.$ and $\phi_{\mathrm{j}}(k)$, respectively, for $\mathrm{j}=\mathrm{O}, \mathrm{Cl}$, and Er) from FEFF8.00. ${ }^{66} \mathrm{In}$ view of the range of $k\left(\AA^{-1}\right)$ data available here $\left(k_{\max }=10.5 \AA^{-1}, \Delta k=8.5 \AA^{-1}, \Delta r=2 \AA\right)$ and the number of independent parameters $\left(\mathrm{N}_{\mathrm{idp}} \approx 12\right),{ }^{67}$ we were easily able to refine eight parameters in the curve fitting of the Er EXAFS for the most complicated response, which came from the electron-yield detector. In order to achieve a balanced backscattering signal amplitude throughout the $k$-space domain, the electron-yield EXAFS were effectually weighted by $k^{2}$. As such, all the EXAFS data were processed and modeled, and are displayed here as $k^{2} \chi(k)$ vs. $k$. Three metrical parameters (interatomic distance, $r$; coordination number, $\mathrm{CN}$; Debye-Waller factor, $\sigma^{2}$ ) and one energy shift parameter $\left(\Delta E_{0}\right)$ were refined for each Er-O term in the one-shell (4 variables) model. The scale factor, $S_{0}^{2}$, was fixed at 0.9 . The constituent elements contributing to additional backscattering shells observed in the electron-yield data were identified in a best-Z curve fitting approach, which clearly indicates the presence of $\mathrm{Cl}^{-}$in the second shell around $\mathrm{Er}^{3+}$. Since the best- $\mathrm{Z}$ fitting works by matching $F_{\mathrm{j}}(k)$ and $\phi_{\mathrm{j}}(k)$ from FEFF with the experimental data, the significant differences between $\mathrm{O}, \mathrm{Cl}$, and Er functions (vs. $k, \AA^{-1}$, see Supporting Information, Fig. 5) facilitates identification of backscattering atoms about Er. The inclusion of $\mathrm{Cl}^{-}$backscattering in the two-shell, 6-parameter model was statistically justified at the $95 \%$ confidence interval 
(pursuant to the method of Downward et al. ${ }^{68}$ ) as was the further addition of $\mathrm{Er}^{3+}$ backscattering in the three-shell, 8-parameter model.

\section{RESULTS AND DISCUSSION}

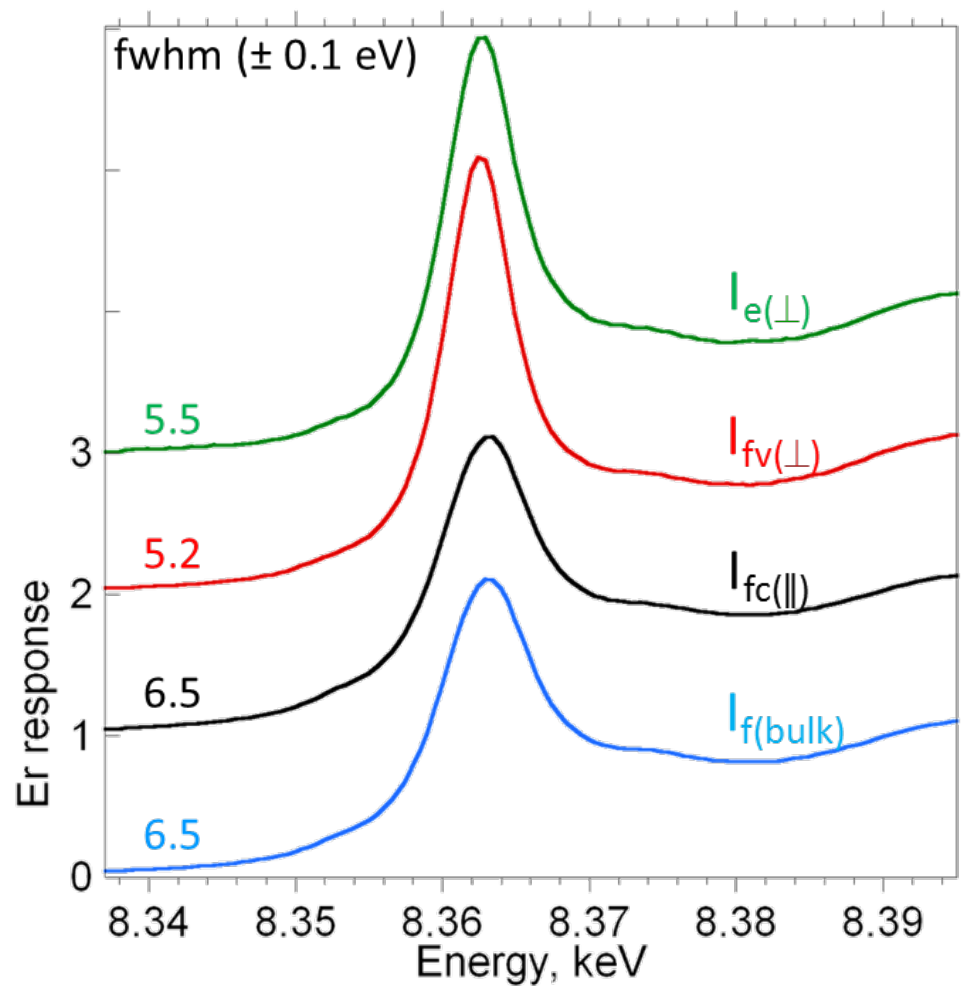

Figure $3 \mathrm{Er} \mathrm{L}_{3}$-edge XANES spectra obtained from a $1.0 \mathrm{M} \mathrm{ErCl}_{3}$ aqueous electrolyte. The blue curve is the bulk fluorescence response, $I_{\mathrm{f}(\mathrm{bulk})}$, with a 1/e escape depth of $300 \mu \mathrm{m}$ measured in the conventional $45 / 45^{\circ}$ configuration transmission geometry. The black curve is the fluorescence obtained in the reflection geometry from the uppermost $45 \AA$ of the electrolyte surface using the Ge-detector aligned parallel to the surface, $\mathrm{I}_{\mathrm{fc}(I)}$. Both of these fluorescence data were obtained with the germanium detector. The red curve is the fluorescence from the uppermost $45 \AA$ of the electrolyte surface using the Si-detector aligned perpendicular to the surface, $\mathrm{I}_{\mathrm{fv}(\perp)}$. The green curve is the electron-yield obtained from the uppermost $31 \AA$ of the electrolyte surface with the 
detector grid aligned perpendicular to the surface, $I_{\mathrm{e}(\perp)}$. The small peak intensities obtained with the Ge detector result from the use of a short shaping time $(0.25 \mu \mathrm{s})$ in comparison with the longer peaking times available with the Si detector. The full width at half maximum (fwhm) values for the edge peaks are shown on the left.

XANES. The Er $\mathrm{L}_{3}$-edge spectra for the bulk and surface responses of the $1.0 \mathrm{M} \mathrm{ErCl}_{3}$ aqueous electrolyte of Figure 3 show an intense edge peak at $8.363 \mathrm{keV}$ that is typical of trivalent $\mathrm{Er}^{69,70}$ The peak intensities for the spectra obtained by use of the fluorescence ( $\mathrm{Si}$ ) and electron-yield detectors perpendicular to the electrolyte surface $\left(\mathrm{I}_{\mathrm{fv}(\perp)}\right.$ and $\mathrm{I}_{\mathrm{e}(\perp)}$, respectively) are approximately $70 \%$ larger than the fluorescence $(\mathrm{Ge})$ response obtained from the detector parallel to it, $\mathrm{I}_{\mathrm{fc}(I)}$, and for $\mathrm{I}_{\mathrm{f}(\mathrm{bulk})}$ as well. This result reflects differences in peaking and shaping times available with the $\mathrm{Si}$ and Ge detector electronics and not to true differences in the occupancy of the nominally empty $5 \mathrm{~d}$-orbital manifold of $\mathrm{Er}^{3+}$, with a ground state electronic configuration of [Xe] $4 \mathrm{f}^{11} 6 \mathrm{~s}^{0} 5 \mathrm{~d}^{0}$. Also, in corresponding fashion, the narrower peak widths of 5.2 and $5.5 \mathrm{eV}$ (see Table 1) obtained from $\mathrm{I}_{\mathrm{fv}(\perp)}$ and $\mathrm{I}_{\mathrm{e}(\perp)}$, respectively, are free of the extrinsic detector artifacts that broaden (6.5 eV fwhm) and compress the edge resonance obtained from $\mathrm{I}_{\mathrm{fc}(\mathrm{II})}$ and $\mathrm{I}_{\mathrm{f}(\mathrm{bulk})}$. Compared to the $4.35 \mathrm{eV}$ natural width of the $\mathrm{Er} \mathrm{L}_{3}$-level, ${ }^{50}$ the larger experimental values reflect intrinsic physico-chemical effects, due to Er coordination wherein linewidths of $\mathrm{L}_{3}$-edge peaks are a convolution of initial state $\left(2 \mathrm{p}_{3 / 2}\right)$ and final state $(5 \mathrm{~d})$ widths. The latter are sensitive to a number electronic influences, most notably due to the ligand-field environment as well as orbital mixing and hybridization due to Er-ligand bonding. ${ }^{69}$ In fact, the small, yet significant, difference between the 5.2(1) eV fwhm obtained for the near-surface $\left(\mathrm{I}_{\mathrm{fv}(\perp)}\right)$ response and the 5.5(1) eV fwhm obtained for the surface $\left(I_{e(\perp)}\right)$ response is a good predictor of variations in the coordination of $\mathrm{Er}^{3+}$ with depth from the surface into the bulk electrolyte. This will be borne out with 
quantitative metrical details about the local environments of $\mathrm{Er}^{3+}$ as obtained through analysis of the EXAFS signal, vide infra. The narrow edge peak resonances and the simple valley shapes of the second differential XANES (see Supporting Information, Fig. 6) show no evidence for ligand-field splitting of the empty $5 \mathrm{~d}$ manifolds, as would be manifest by wide edge peak resonances and double valley shapes of the second differential data, such as found for $6 \mathrm{O}$ coordination to $\mathrm{Er}^{3+}$ with octahedral symmetry. Precedent is provided by the observations made here and elsewhere ${ }^{69-71}$ by use of $\mathrm{Er}_{3}$-edge electron-yield XANES. The surface response for the two solids of $\mathrm{ErCl}_{3} \cdot 6 \mathrm{H}_{2} \mathrm{O}$ and $\mathrm{Er}_{2} \mathrm{O}_{3}$ reveal edge resonances of 5.2 and $7.2 \mathrm{eV}$ fwhm, respectively (see Supporting Information, Fig. 7). The corresponding second differential XANES for $\mathrm{ErCl}_{3} \cdot 6 \mathrm{H}_{2} \mathrm{O}$ shows a single valley, consistent with no d-state splitting as expected for the 8coordinate $\mathrm{Er}^{3+}$ ion. ${ }^{72-74}$ In contrast, the data for $\mathrm{Er}_{2} \mathrm{O}_{3}$ reveals a double valley structure, consistent with d-state splitting as expected for the $6 \mathrm{O}$ coordination of $\mathrm{Er}^{3+}$ (see Supporting Information, Fig. 7). ${ }^{75,76}$ Although ligand-field effects are certainly at play for the liquid electrolyte system studied here, they are smaller than the spectral resolution of the beamline optics - suggesting an $\mathrm{O} \mathrm{CN}$ greater than six - and, therefore, cannot be resolved in the second differential of the XANES data.

Table 1. Er $\mathrm{L}_{3}$-edge peak linewidths (full width at half maximum) and positions (both in $\mathrm{eV}( \pm$ 0.1)) as well as intensities as obtained by fitting the normalized XANES data of Figure 3 in the most conservative manner possible. The data were modeled with 2 components that correspond to the number of observed spectral features, namely an arctangent to account for the edge rise and one Gaussian-shaped peak to account for the edge peak. The detector orientations are shown in Figure 1. 


\begin{tabular}{|c|c|c|c|c|c|c|}
\hline & \multicolumn{3}{|l|}{ Gauss } & \multicolumn{3}{|l|}{ Arctan } \\
\hline Response & fwhm & position & height & fwhm & position & height \\
\hline $\mathrm{I}_{\mathrm{f} \text {,bulk }}{ }^{\mathrm{a}}$ & 6.5 & 8363.1 & 1.32 & 13.0 & 8356.0 & 0.93 \\
\hline $\mathrm{I}_{\mathrm{fc}}, \|^{\mathrm{b}}$ & 6.5 & 8363.1 & 1.29 & 13.4 & 8355.6 & 0.97 \\
\hline $\mathrm{I}_{\mathrm{fv}}, \perp^{\mathrm{c}}$ & 5.2 & 8362.6 & 2.26 & 11.2 & 8355.2 & 0.90 \\
\hline $\mathrm{I}_{\mathrm{e}, \perp}{ }^{\mathrm{d}}$ & 5.5 & 8362.7 & 2.11 & 9.3 & 8356.4 & 0.90 \\
\hline
\end{tabular}

a Obtained in the conventional $45^{\circ}-45^{\circ}$ incident-exit geometry with Ge detector (Canberra) of solution contained in SPEX micro X-cell (\# 3577).

b Obtained under conditions of grazing incidence and total external reflection with the Ge fluorescence detector (Canberra) element aligned parallel to the electrolyte surface.

c Obtained under conditions of grazing incidence and total external reflection with the $\mathrm{Si}$ fluorescence detector (Vortex-ME4) element aligned perpendicular the electrolyte surface.

d Obtained under conditions of grazing incidence and total external reflection with the total electron-yield detector grid aligned perpendicular the electrolyte surface.

EXAFS. The background-subtracted data, $k^{2} \chi(k)$ vs. $k$, for the bulk and surface responses of the 1.0 $\mathrm{M} \mathrm{ErCl}_{3}$ aqueous electrolyte shown in Figure 4 (left, solid lines) demonstrate that the experimental response obtained by electron yield is unique. Whereas all of the other data can be adequately modelled as a single, damped sinusoid (Figure 4, left, dashed lines), typical of oxygen backscattering for the aquated $\mathrm{Er}^{3+}$ cation, there is evidence for multiple sinusoidal components 
in the electron yield response. This qualitative observation suggests that the Er ions within the
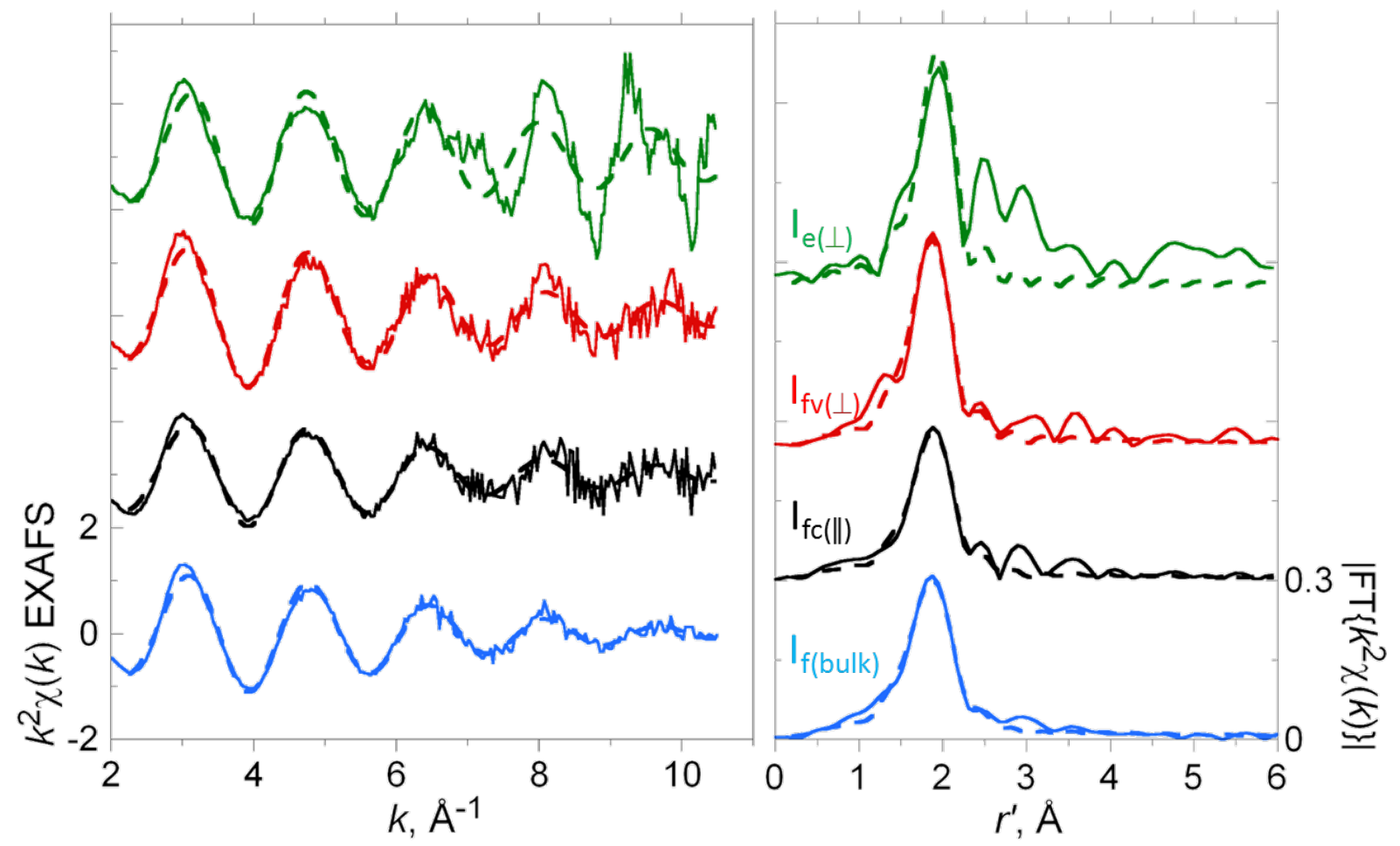

Figure 4 Left panel: The $k^{2}$-weighted $\mathrm{Er}^{3+}$ EXAFS obtained from experiment (solid lines) and the single-O shell fits (dashed lines). Right panel: The corresponding FT data, which are uncorrected for phase shift as shown, from experiment (solid lines) and fits (dashed lines). The total-electronyield (green lines) and fluorescence data (red and black lines) collected from the $1 \mathrm{M} \mathrm{ErCl}_{3}$ electrolyte surface-as described in the caption to Figure 3-are compared with the fluorescence data collected for the bulk $1 \mathrm{M} \mathrm{ErCl}_{3}$ electrolyte (blue lines).

scattering volume sampled by electron-yield ( $\leq 31$ Å below the surface) have more correlations than do the Er ions within the much larger scattering volume sampled by fluorescence ( $\leq 45 \AA$ below the surface). The Fourier transform (FT) data of the $k^{2} \chi(k)$ EXAFS bears out the differences in the vicinities of $\mathrm{Er}^{3+}$. In Figure 4 (right, solid lines), the intense peaks at ca. $1.9 \AA$ (phase shift uncorrected distance) in all four panels are attributable to backscattering from the 
innermost $\mathrm{O}$ atoms about Er. The FT data for the electron yield EXAFS reveal two distant peaks of physical significance at ca. 2.5 and $3.0 \AA$, which are indicative of second and third sphere correlations, e.g., Er-X where $\mathrm{X} \quad \mathrm{O}, \mathrm{Cl}, \mathrm{Er} .{ }^{77}{ }^{78-80}$ In comparison, the FTs of the fluorescence data $\left(\mathrm{I}_{\mathrm{fv}(\perp)}\right.$ and $\left.\mathrm{I}_{\mathrm{fc}(\mathrm{II})}\right)$ show weak distant features that are consistent with the peak positions in the $\mathrm{I}_{\mathrm{e}(\perp)}$ response. The small peak intensities suggest that the fluorescence data arises from the combination of a significant amount of bulk electrolyte response, as shown by $\mathrm{I}_{\mathrm{f}(\mathrm{bulk})}$, with a minor amount of the surface response as probed by $\mathrm{I}_{\mathrm{e}(\perp)}$. In other words, the fluorescence response samples a good deal of the correlations in the bulk electrolyte, for which there is no statistically meaningful evidence for outer sphere associations of the kind seen through use of $\mathrm{I}_{\mathrm{e}(\perp)}$. For the purposes of understanding the penetration-depth dependence to the $\mathrm{Er}^{3+}$ solvation, efforts were first directed at obtaining quantitative information about the $\mathrm{Er}^{3+}$ environs in terms of the nearest Er-O interactions - including bond lengths and Debye-Waller factors as well as O coordination numbers - through curve fitting analysis of the $k^{2} \chi(k)$ EXAFS.

Table 2. Results of the one-shell (oxygen), four-parameter curve fitting to the $k^{2} \chi(k) \mathrm{Er} \mathrm{L}_{3}$-edge EXAFS data Fig. 4.

\begin{tabular}{lllll}
\hline & \multicolumn{4}{c}{ Er Response } \\
\cline { 2 - 5 } Parameter $^{\mathrm{a}}$ & $\mathrm{I}_{\mathrm{f} \text {, bulk }}(\mathrm{Ge})$ & $\mathrm{I}_{\mathrm{fc}}, \|(\mathrm{Ge})$ & $\mathrm{I}_{\mathrm{fv}, \perp}(\mathrm{Si})$ & $\mathrm{I}_{\mathrm{e}, \perp}$ \\
\hline$C N^{\mathrm{b}}$ & 7.4 & 6.1 & 8.2 & 7.0 \\
$r, \AA^{\mathrm{c}}$ & 2.33 & 2.34 & 2.33 & 2.37 \\
$\sigma^{2}, \AA^{2 \mathrm{~d}}$ & 0.009 & 0.007 & 0.006 & 0.002 \\
$\Delta E_{0}, \mathrm{eV}^{\mathrm{e}}$ & -2.9 & -2.5 & -3.5 & -0.8
\end{tabular}

${ }^{\mathrm{a}}$ Three metrical parameters (coordination number, $C N$; interatomic distance, $r$; Debye-Waller factor, $\left.\sigma^{2}\right)$ and one energy shift parameter $\left(\Delta E_{0}\right)$. ${ }^{\mathrm{b}}$ Estimated standard deviation (esd) at the $3 \sigma-$ level is \pm 1 . $^{\mathrm{c}}$ esd is $\pm 0.01 \AA$. ${ }^{\mathrm{d}}$ esd is $\pm 0.002 \AA^{2}$. ${ }^{\mathrm{e}}$ esd is $\pm 0.5 \mathrm{eV}$. 
The $\mathbf{O}$ environment of $\mathbf{E r}^{3+}$. A conservative, 4-parameter, single-O shell analysis was employed to model all the EXAFS. The metrical results for the Er-O correlation are collected in Table 2, and the individual fits are shown in Figure 4 as dashed lines. The results for the bulk solution of the aquated $\mathrm{Er}^{3+}$ ion with $7.4 \pm 1 \mathrm{O}$ at 2.33(1) $\AA$ agree with a significant body of experimental literature on the aqueous speciation of Er in acid media, ${ }^{30,43-48}$ and specifically with HEXS results from a similar solution. ${ }^{30}$ The latter found $8.1 \pm 0.2$ waters about Er at a distance of 2.357(5) A. In so far as bond lengths can be used as indicators of coordination numbers, the EXAFS experimental value of 2.33(1) $\AA$ is intermediate of the mean Er-O bond distance of 2.30 $\AA$ for $\mathrm{CN}=7$ and the mean distance of $2.35 \AA$ for $\mathrm{CN}=8$; the latter two values were obtained from analyses of solid state and solution structure data for Er complexes with neutral O donor ligands, including $\mathrm{H}_{2} \mathrm{O} .^{81}$ The Er-O distances of 2.33-2.34 $\AA$ obtained from the fluorescence EXAFS obtained at grazing incidence conditions $\left(\mathrm{I}_{\mathrm{fc}(\mathrm{II})}\right.$ and $\left.\mathrm{I}_{\mathrm{fv}(\perp)}\right)$ are identical with that for the bulk response, $\mathrm{I}_{\mathrm{f}(\mathrm{bulk})}$, suggesting that the solution volume sampled by $\mathrm{I}_{\mathrm{fc}(I)}$ and $\mathrm{I}_{\mathrm{fv}(\perp)}$ contains a significant fraction of the monodisperse, aquated cation, $\left[\mathrm{Er}\left(\mathrm{OH}_{2}\right)_{8}\right]^{3+}$. The $6.1 \pm 1 \mathrm{O} \mathrm{CN}$ for the $\mathrm{I}_{\mathrm{fc}(I)}$ response is unexpectedly low when compared to the average Er-O distance of 2.34(1) $\AA$, suggesting the possibility of some polarization dependence to the near-surface environment of $\mathrm{Er}^{3+}$ as can result from, for example, linear O-M-O scattering paths ${ }^{82}$ Support for this suggestion comes from the results of Table 2 showing that the bulk $\mathrm{O} \mathrm{CN}$ of 7.4, which is not affected by polarization, is nearly the mean value of the $\mathrm{I}_{\mathrm{fc}(I)}$ and the $\mathrm{I}_{\mathrm{fv}(\perp)} \mathrm{O}$ CNs of 6.1 and 8.2, respectively. The electron yield EXAFS was best fit with $6.8 \pm 1 \mathrm{O}$ atoms at an average distance of 2.36(1) $\mathrm{\text {, }}$ which is $0.03-0.04 \AA$ longer than the values from fluorescence EXAFS, and approaching the $2.39 \AA \mathrm{Ar}-\mathrm{O}$ distance that is diagnostic of $\mathrm{CN}=9 .{ }^{81}$ The fact that the Er-O distance is longer than 
expected for both 7- and 8-coordinate $\mathrm{Er}^{3+}$ ions suggests the presence of additional atoms other than $\mathrm{O}$ in the coordination sphere, vide infra.

The distant environment of $\mathbf{E r}^{3+}$ in the $\mathbf{I}_{\mathbf{e}(\perp)}$ response. Because the electron-yield EXAFS data are not satisfactorily modelled with the single-O shell analysis and, most important, the presence of two distant fully-resolved peaks in the FT data of Figure 4, the EXAFS spectrum was fit in an incremental fashion with two- and three-shell models. With these, the first shell is due to O exactly as described above; the second one, responsible for the peak at ca. $2.5 \AA$ in the FT data, was identified to arise from backscattering by 2.6(5) $\mathrm{Cl}$ at an average distance of 2.90(2) $\AA$ around $\mathrm{Er}^{3+}$. This average $\mathrm{Er}-\mathrm{Cl}$ distance is longer, albeit consistent, with those observed previously in solution $(2.65-2.67 \AA)^{48}$ and in the solid state structure $(2.73 \AA)$ of $\mathrm{ErCl}_{3} \cdot 6 \mathrm{H}_{2} 0$, in which Er is 8-coordinate as the cation $\left[\left(\mathrm{H}_{2} \mathrm{O}\right)_{6} \mathrm{ErCl}_{2}\right]^{+}$with $6 \mathrm{Er}-\mathrm{OH}_{2}$ and $2 \mathrm{Er}-\mathrm{Cl}$ bonds. ${ }^{74}$ Coincidentally, this molecular cation has an average Er-O distance of $2.36 \pm 0.03 \AA$ that is statistically equivalent to the one found here (2.37 $\AA$ ), see Supporting Information (Table 1). This agreement suggests that the $\mathrm{Er}^{3+}$ ions at the surface of the electrolyte are in the form of mixed aqua-chloro coordination complexes. The two-shell fit and the metrical parameters, which indicate 9-coordinate $\mathrm{Er}^{3+}$ with $6.4 \mathrm{O}$ and $2.6 \mathrm{Cl}$, are provided as Supporting Information (see Figure 8 and Table 1). 


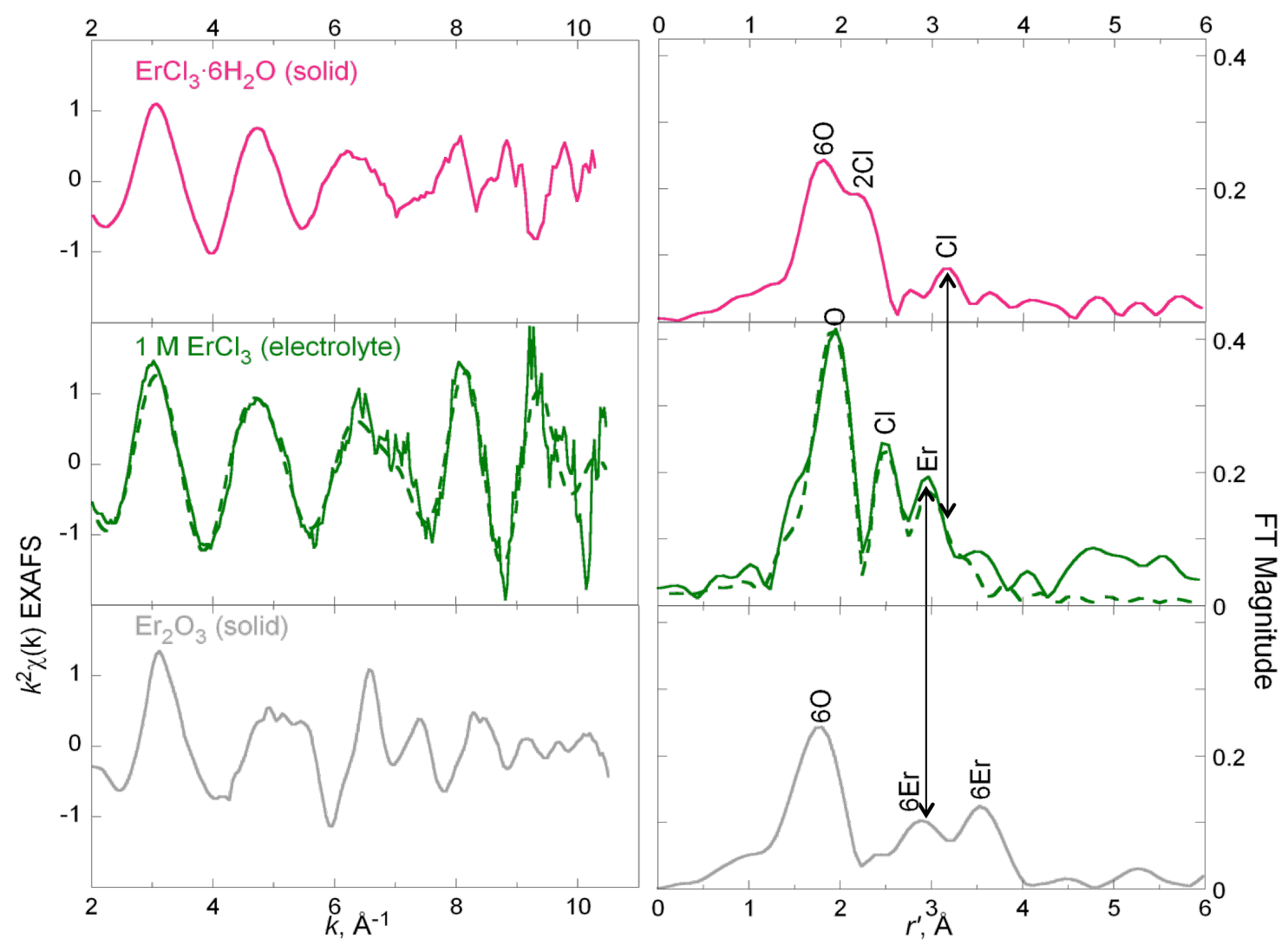

Figure 5 Left panel: Comparison of the experimental $k^{2}$-weighted $\mathrm{Er}^{3+}$ EXAFS collected by totalelectron-yield from surface of the $1 \mathrm{M} \mathrm{ErCl}_{3}$ aqueous electrolyte (solid green line) with the corresponding data for solid powders of $\mathrm{ErCl}_{3} \cdot 6 \mathrm{H}_{2} \mathrm{O}$ (pink line) and $\mathrm{Er}_{2} \mathrm{O}_{3}$ (gray line) collected and analyzed in identical fashion. Right column: The corresponding FT data, which are uncorrected for phase shift as shown, from experiment (solid lines); the dashed green lines show the three-shell fit to the $k^{2} \chi(k)$ EXAFS and FT for the electrolyte solution, where the identification of the $\mathrm{O}, \mathrm{Cl}$, and Er peaks are compared with those in the FT data for the solid specimens of known structures.

The identification of the third peak in the FT data at ca. 3.0 A through use of the best-Z fitting approach was less obvious than the approach leading to the clear identification of $\mathrm{Cl}$ backscattering. At longer distances, there is greater spectral congestion than at shorter ones, and 
a combination of two (or more) backscattering paths, Er-X for $\mathrm{X}=\mathrm{O}, \mathrm{Cl}$, and Er, is likely. To facilitate identification, the data of Figure 5 provides a comparison of the $\mathrm{I}_{\mathrm{e}(\perp)}$ response for the liquid electrolyte with the conversion electron yield data for the $\mathrm{ErCl}_{3} \cdot 6 \mathrm{H}_{2} \mathrm{O}$ and $\mathrm{Er}_{2} \mathrm{O}_{3}$ solids with known structures. In the FTs (right, without phase shift correction), the third peak in the electrolyte response is a near-exact match with the short Er-Er correlation peak in $\mathrm{Er}_{2} \mathrm{O}_{3}$. Consistent with this observation, and in considering the contribution from just a single backscattering element, the EXAFS signal was best modelled in the best-Z approach with 3.3(5) Er at an average distance of 3.20(2) $\AA$. This distance is $8.5 \%$ shorter than the average Er-Er distance reported for the solid-state structure of $\mathrm{Er}_{2} \mathrm{O}_{3}$ with $6 \mathrm{Er}$ at $3.496 \AA \AA^{75}$ The contraction for the liquid electrolyte is correlated with the decrease in the number of Er nearest neighbors with respect to that for the solid oxide. The three shell fit to the $I_{\mathrm{e}(\perp)}$ EXAFS for the liquid electrolyte is shown as dashed lines in Figure 5, and the metrical results are provided in the Supporting Information (see Table 2).

Profound differences between surface and bulk speciation of $\mathbf{E r}^{3+}$. The grazing-incidence, electron-yield EXAFS data probe the Er environment at the electrolyte-helium interface with greater surface sensitivity than is achieved with fluorescence measurements. The escape depth of the $\mathrm{I}_{\mathrm{e}}$ response is approximately $31 \AA$, which is some $15 \AA$ shallower than the evanescent wave and the 1/e escape depth of Er $\mathrm{L}_{\alpha}$ fluorescence photons. As a consequence, a two-point depth profile of the interfacial Er speciation is afforded by the simultaneous acquisition of conversion electron yield and X-ray fluorescence data. Whereas the fluorescence data are typical of an aquated $\mathrm{Er}^{3+}$ cation (much like the bulk electrolyte speciation, $\left.\mathrm{Er}\left(\mathrm{OH}_{2}\right)_{8}{ }^{3+}\right)$, the conversion electron yield response reveals unexpected correlations arising from approximately 3 distant $\mathrm{Cl}^{-}$ (at 2.89-2.90 ̊) and approximately 3 distant $\mathrm{Er}^{3+}$ ions (at $3.20 \AA$ ) that are not detected in the 
fluorescence response. In previous studies of water-air interfaces by use of XAS under grazing incidence conditions comparable to ours, dubbed total reflection total conversion $\mathrm{He}^{+}$ion-yield (TRTCY-XAS), ${ }^{52-56,83-87}$ the coordination environments about cations (e.g., $\mathrm{Cu}^{2+}$ and $\mathrm{Zn}^{2+}$ ) and anions (e.g., $\mathrm{Br}^{-}$) at the surface are oftentimes different from that in the bulk. In fact, the differences are manifest in the same manner as observed here, where the surface species response exhibits correlations beyond the innermost solvation sphere and at long distances (typically between 3.2 and $5 \AA$ ) that are absent in the bulk coordination. ${ }^{56,85-87}$ This is contrary to the inherent sensitivity of the EXAFS response, which decreases with increasing distance because of the combined effects of signal amplitude reduction due to a $1 / \mathrm{r}^{2}$ dependence; exponential dampening contributions from disorder as manifest in the Debye-Waller effect; polydispersity of coordination environments, and; fluxional interatomic correlations. ${ }^{17}$ The combination of these effects makes the detection of distant coordination spheres in EXAFS acquired at room temperature for electrolyte solutions of aquated cations an uncommon occurrence. As such, the strong, distant shells of $\mathrm{Cl}$ and $\mathrm{Er}$ in the FT data obtained by electronyield EXAFS (Figure 4, green lines) are rationalized by the formation of Cl- and Er-rich domains at the electrolyte $-\mathrm{He}$ interface. The enrichment of $\mathrm{Er}^{3+}$ in the scattering volume probed here by use of the $\mathrm{I}_{\mathrm{e}(\perp)}$ response has recently been demonstrated by complementary X-ray reflectivity measurements. ${ }^{35}$ The nucleation of interconnected islands of charge-neutral $\mathrm{Er}^{3+}$-aqua-chloro complexes is depicted to be driven by hydrolysis-type reactions at the electrolyte surface that promote condensation of polynuclear species ${ }^{88}$ and that do not otherwise occur in the bulk electrolyte. A structural scenario that emerges from the $\mathrm{I}_{\mathrm{e}(\perp)}$ GI-EXAFS results to account for the observed Er-O and Er-Cl correlations is the growth of neutral $\left[\left(\mathrm{H}_{2} \mathrm{O}\right)_{6-7} \mathrm{ErCl}_{3}\right]$ surface species. In similar fashion, the trivalent lanthanide ( $\mathrm{Ln}$ ) ions $\mathrm{La}$ and $\mathrm{Gd}$ bind to solid silica surfaces in a 
decreased (i.e., near neutral) charge state due to the formation of strong $\mathrm{Ln}^{3+} \cdot \mathrm{Cl}$ complexes. ${ }^{89} \mathrm{To}$ further account for the presence of the three Er-Er correlations, the aforementioned $\mathrm{Er}-\mathrm{H}_{2} \mathrm{O}-\mathrm{Cl}$ entities would have to exhibit strong intermolecular associations, such as through bridging $\mathrm{Cl}^{-}$ and/or $\mathrm{OH}^{-}$ions. One of the many ways to envision this is through the formation of cluster entities $^{90-92}$ with polynuclear (i.e., binuclear, tetranuclear, etc.,) core components. For example, we can envisage a tetranuclear $\mathrm{Er}^{3+}$-entity in the shape of a cube, wherein four opposite corners are occupied by $\mathrm{Er}^{3+}$ cations and the other four corners are occupied by either $\mathrm{OH}^{-}$and/or $\mathrm{O}^{2-}$ anions. In such a rudimentary geometry (as shown in Figure 6 a), each $\mathrm{Er}^{3+}$ ion would have three close $\mathrm{O}$ neighbors and 3 distant Er neighbors. The balance of 3-4 $\mathrm{O}$ atoms (to account for the total $\mathrm{O} \mathrm{CN}$ of 6-7) and the $3 \mathrm{Cl}$ atoms (to account for the $\mathrm{Cl} \mathrm{CN}$ of 3) would arise from water and chloride
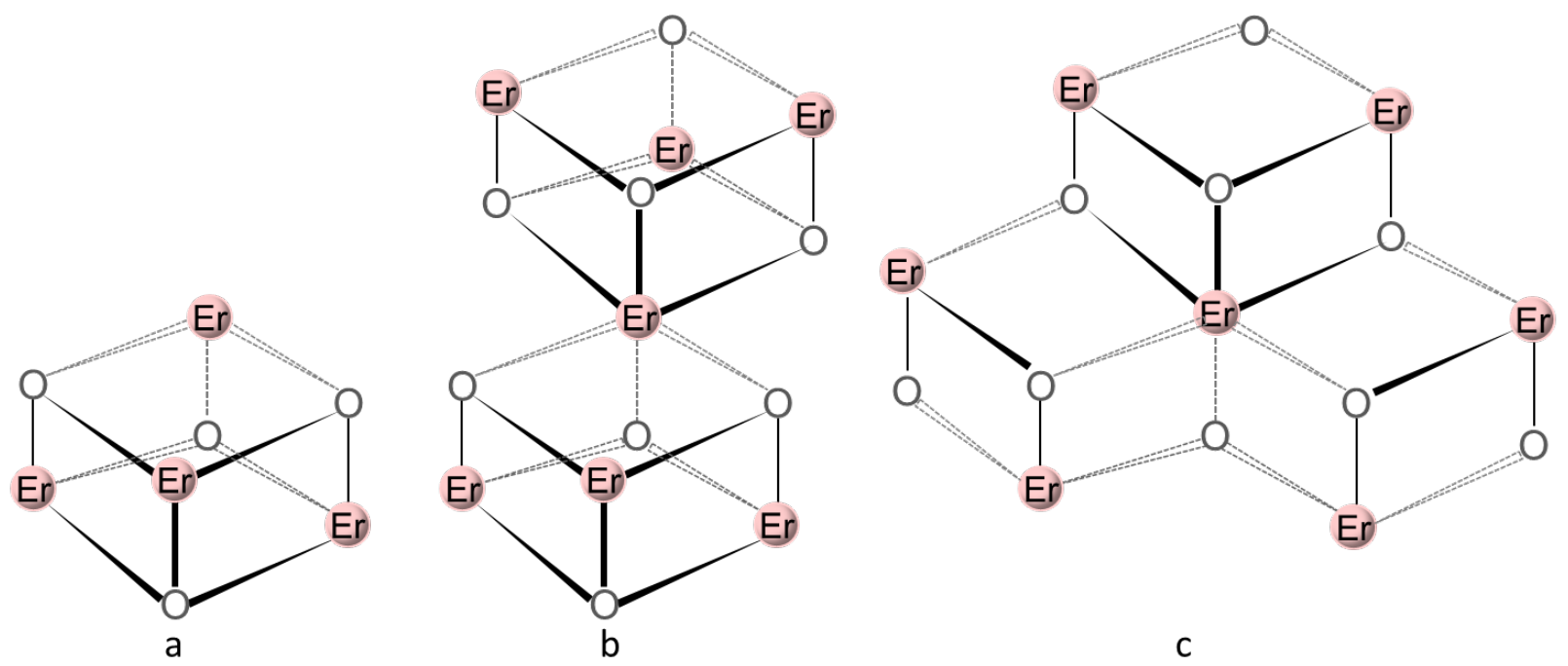

Figure 6(a) $\left\{\mathrm{Er}_{4} \mathrm{O}_{4}\right\}$ cubane core; each $\mathrm{Er}$ has $3 \mathrm{Er}$ neighbors. (b) two $\left\{\mathrm{Er}_{4} \mathrm{O}_{4}\right\}$ cubane cores connected by a corner Er to form a $\left\{\mathrm{Er}_{7} \mathrm{O}_{8}\right\}$ core structure. The common corner $\mathrm{Er}$ has $6 \mathrm{Er}$ neighbors; the 6 other Er ions have 3 Er neighbors, providing an average $\mathrm{Er} \mathrm{CN}$ of 3.4. (c) three $\left\{\mathrm{Er}_{3} \mathrm{O}_{4}\right\}$ cubane-like cores (with three missing corners) connected by edges to form a $\left\{\mathrm{Er}_{7} \mathrm{O}_{9}\right\}$ 
core structure in which the $7 \mathrm{Er}$ ions are essentially planar. The central Er has 6 Er neighbors; the 6 other Er ions have $3 \mathrm{Er}$ neighbors, providing an average $\mathrm{Er} \mathrm{CN}$ of 3.4. The experimentallydetermined $\mathrm{Er} \mathrm{CN}$ is $3.3 \pm 1$. Terminal chloride ions and water molecules attached to $\mathrm{Er}(\mathrm{III})$ are not shown. The planar geometry of (c) may be more adaptable to the surface of the electrolyte than either of the geometries in (a) and (b).

positioned around the exterior of the $\left\{\mathrm{Er}_{4} \mathrm{O}_{4}\right\}$ core unit. There is considerable precedent in the literature for tetranuclear erbium-hydroxo clusters with cube-like core architectures. ${ }^{93-97}$ These so-called cubane structures, which are common throughout the lanthanide period ${ }^{98}$ as are hexanuclear ones,${ }^{99,100}$ are obtained by hydrolysis reactions of aqueous electrolyte solutions of $\mathrm{ErCl}_{3}$. The presence of tetranuclear Er species at the electrolyte surface is consistent with the purported surface basicity, which would facilitate hydrolysis and the formation of cubane-like building blocks (Figure 6 a) and their subsequent aggregation into edge- and corner-sharing structure motifs (Figure $6 \mathrm{~b}$ and 6c, respectively) comparable to the molecular cluster models of cobalt-phosphate water-oxidation catalysts. ${ }^{101}$ Nonetheless, from the one-dimensional perspective afforded by EXAFS, it is not possible to confirm the presence of three-dimensional erbium cubane cluster motifs. For this, the use of other GI X-ray methods, like HEXS (highenergy X-ray scattering), would provide a complete and descriptive picture of the Er aggregate morphology, including $\mathrm{H}$ atom correlations, such as done for the speciation of ions in bulk solutions. $^{20,22,30,102-106}$

The defining aspect of the metrical information obtained by $\mathrm{I}_{\mathrm{e}(\perp)}$ GI-EXAFS concerns the average Er-Er correlation distance. The one observed here, 3.20(2) $\AA$, is shorter than the range of Er-Er interactions (3.44-3.92 $\AA$ ) found for tetra- and hexa-nuclear Er cluster moieties, a situation that may reflect the inherent differences between surface structures at electrolyte-vapor interfaces and 
bulk ones. Furthermore, the prominence of the distant $\mathrm{Cl}$ and $\mathrm{Er}$ correlation peaks in the FT data obtained by electron-yield EXAFS (Figures 4 and 5, green solid lines) may arise from a preferred orientation of the $\mathrm{Er}^{3+}-\left(\mathrm{H}_{2} \mathrm{O}\right)_{6-7}-\mathrm{Cl}_{3}$ complex at the very surface of the electrolyte-helium interface, where the photoelectron backscattering is focused by the orientation of intervening ions ${ }^{107}$ and amplified by the polarization of the incident beam. ${ }^{82}$ To understand the exact morphology and orientation of the $\mathrm{Er}^{3+}$ surface complexation at the liquid-helium interface for the $\mathrm{ErCl}_{3}$ electrolyte, additional information, such as may be obtained by use of optical luminescence measurements, is essential. Nevertheless, now we can combine the local structural information as obtained here from EXAFS regarding the cubane clusters of $\mathrm{Er}^{3+}$ shown in Figures 6 and 7(a) to model the experimental intrinsic electron density profiles obtained previously from X-ray reflectivity measurements. ${ }^{35}$ By so doing, we are able to estimate the interfacial density of these model cluster systems. The intrinsic electron density determined from reflectivity, shown Figure 7(b), shows three distinct features: 1) A depletion region $(0<z<\sim 7$ A) with an electron density close to that for the bulk density of water, $0.336 \mathrm{e}^{-} \AA^{-3} .2$ ) The bulk electrolyte solution for $z>\sim 20 \AA$ with an electron density of $\left.\sim 0.38 \mathrm{e}^{-} \AA^{-3} .3\right)$ The oscillatory region between $7<z<20 \AA \AA$ indicating the enhancement of $\mathrm{Er}^{3+}$ ions compared to the bulk electrolyte. The surface-EXAFS data indicate that there are correlated $\mathrm{Er}^{3+}$ structures within the depth of $z \leq 31 \AA$ that are not present in the bulk electrolyte $(z>20 \AA)$ and, furthermore, that these correlated structures are manifest as enhanced $\mathrm{Er}^{3+}$ regions. The two-dimensional nature of the model triple-cubane-like cluster, as shown in Figures 6(c) and 7(a), makes it favorable to be aligned with the electrolyte surface as shown in Figure 7(b). Assuming such an alignment at the depth obtained from the X-ray reflectivity data, we calculated the electron density contribution in the first layer of surface-enhanced region (3) arising from the $\mathrm{Er}^{3+}$ cluster motif, in which the 
electrons are confined within the ionic radii of each atom present in the cluster. In that case, the electron density integrated over the $x y$-direction and as a function of depth, $z$, can be written as: $\rho(z)=\frac{\operatorname{cov}}{\pi R_{c}^{2}}\left\{\sum_{i} \frac{z_{i}\left(1-\left(z-z_{i}\right)^{2} / R_{i}^{2}\right)}{4 \pi R_{i}^{3} / 3}\right\} \otimes \exp \left(-\frac{z^{2}}{2 \sigma^{2}}\right)+(1-c o v) \times b u l k+$ depletion region. Here ' $Z_{i}$ ' and ' $z_{i}$ ' are the number of electrons and the $z$-coordinates, respectively; ' $R_{i}$ ' are the ionic radii for the $\mathrm{Er}^{3+}$ and $\mathrm{O}^{2-}$ ions $\left(0.89\right.$ and $1.4 \AA$, respectively $\left.{ }^{108}\right)$ in the clusters; ' $\Sigma_{I}$ ' indicates summing over all the ions of the cluster; $R_{c}$ is the radius of the circle with minimum area required to encapsulate the cluster as shown in Figure 7(a); ' $c o v$ ' is the fractional surface area covered by the clusters, such that $\operatorname{cov}=1.0$ means $100 \%$ coverage of the surface by the clusters; ' $\otimes$ ' indicates the function is further convoluted with an exponential function with a width, $\sigma$, which is the Debye-Waller factor due to the thermal fluctuation of the ions about their mean

a

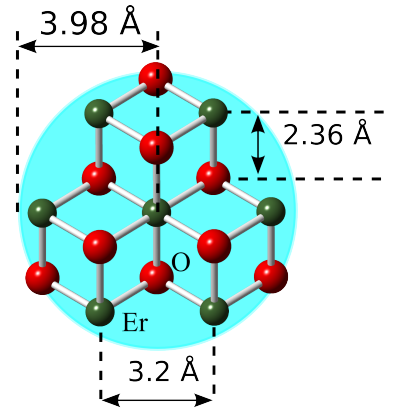

b

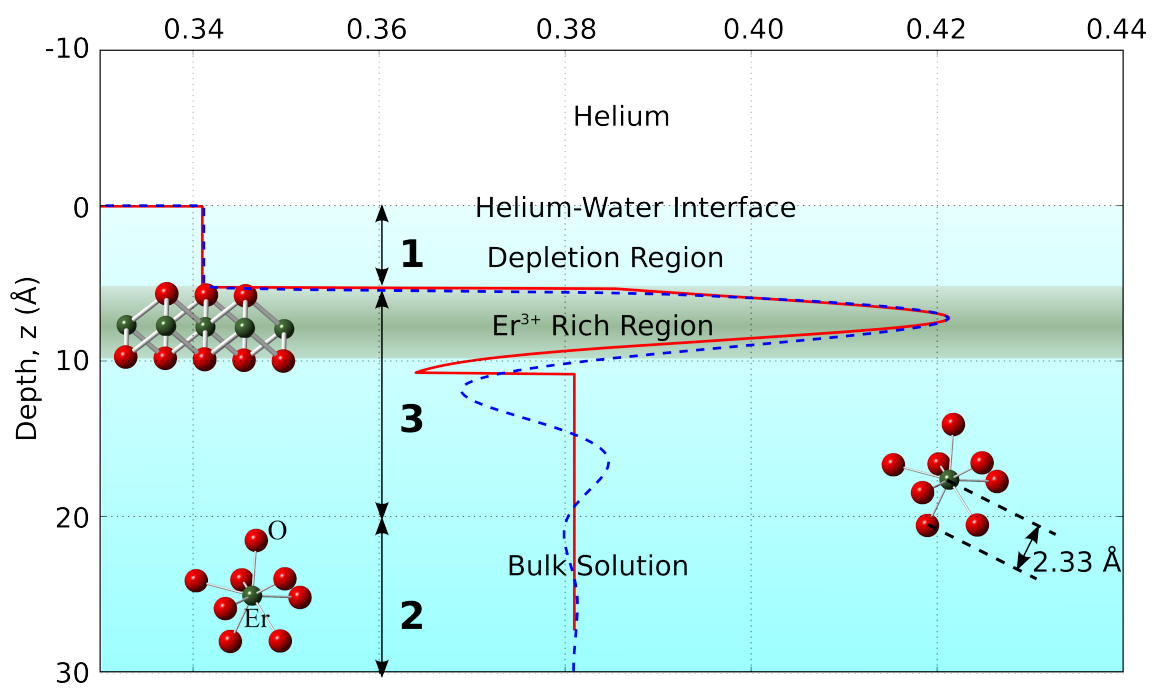

Figure 7(a) The top or $x y$-plane view of the three $\left\{\mathrm{Er}_{3} \mathrm{O}_{4}\right\}$ cubane core structures forming the

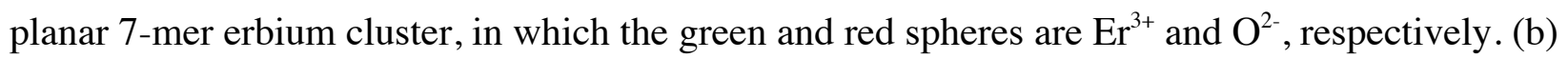
Intrinsic electron density profile (solid red line) as a function of depth calculated by assuming the 
planar erbium clusters to be aligned along the $x y$-plane and at the depth predicted from X-ray reflectivity measurements (blue dashed line) from Luo et al. ${ }^{35}$

positions. Apart from the cluster contributions, there are constant contributions from the bulk and depletion regions ( 2 and 1, respectively, in Figure $7 \mathrm{~b}$ ) as well. The main contribution $(91.5 \%)$ of the clusters to the electron density arises from the $\mathrm{Er}^{3+}$ and $\mathrm{O}^{2-}$ ions, due to the high atomic number of $\mathrm{Er}(68)$ and $9 \mathrm{O}^{2-}$ ions per cluster and, the contribution from $3 \mathrm{Cl}^{-}$ions is $8.5 \%$. As the exact locations of the $\mathrm{Cl}^{-}$ions with respect to the Er-O cluster are not known, we neglect the contribution of $\mathrm{Cl}^{-}$ion in the electron density calculation in the first approximation, and that will result in maximum of $8.5 \%$ overestimation of the coverage parameter 'cov' of the clusters near the air-water interface. The electron density calculated from the equation above, neglecting the contribution of $\mathrm{Cl}^{-}$ion, is shown as the solid red line in Figure 7(b). It closely resembles the first $\mathrm{Er}^{3+}$ enriched layer of experimental electron density (shown as a dashed blue line in Figure 7b) determined from the X-ray reflectivity measurements. ${ }^{35}$ The coverage and the width of the Debye-Waller factor for the best calculated match with the experimental intrinsic electron density profile amount to $5.1 \%$ and $1.3 \AA$, respectively. This low coverage and the large magnitude of the fluctuations, which are greater than the ionic radii, suggest that the cluster motifs formed at the interface are dynamic in nature.

\section{CONCLUSIONS}

The coordination chemistry of metal ions in bulk electrolyte solutions - aqueous and organic alike - and at their surfaces plays critical roles in the molecular reactions of solvent extraction (SX). Despite its wide use for metal purification, notably of the rare-earth family of elements, which are of contemporary interest, not the least of which includes national security, there is 
little understanding of liquid-surface structures in SX. We chose to study $\operatorname{Er}(Z=68)$ because it is a small lanthanide with a well-known coordination environment in bulk aqueous electrolytes. Although the bulk coordination is an important aspect of the overall energetics that influence its $\mathrm{SX}$, the $\mathrm{Er}^{3+}$ speciation at the liquid-liquid interface, where the phase transfer of $\mathrm{Er}^{3+}$ occurs, is not fully understood. In our first step to probe the complicated, multicomponent process of SX, and to simplify the experiment, we examined the liquid-helium interface of an aqueous, acidic $\mathrm{ErCl}_{3}$ electrolyte by use of X-ray absorption spectroscopy using electron-yield and fluorescence detection under conditions of grazing-incidence and total external reflection. In parallel, a comparison of the bulk speciation of the same electrolyte, using fluorescence detection at normal incidence, was presented. With this approach, we found significant differences in the speciation of Er in the bulk and at the surface of the $1 \mathrm{M} \mathrm{ErCl}_{3}$ electrolyte. The interfacial Er speciation cannot be attributed to the bulk speciation, in the form of the aquated cation $\operatorname{Er}\left(\mathrm{OH}_{2}\right)_{8}{ }^{3+}$, and vice versa. The research advances our understanding of the atomic-level, surface-speciation of $\mathrm{Er}^{3+}$ in an electrolyte of practical relevance to hydrometallurgy. In particular, details of the electronyield experiments provided unexpected results that would have been missed by use of GI-XAS with fluorescence detection alone; namely the evidence for conspicuous $\mathrm{Er}-\mathrm{Cl}$ and $\mathrm{Er}-\mathrm{Er}$ correlations within about $30 \AA$ of the electrolyte-helium interface. Electron density calculations in combination with the experimental X-ray reflectivity data are consistent with about $5 \%$ coverage of the electrolyte surface with an $\left\{\mathrm{Er}_{7} \mathrm{O}_{9}\right\}$ cluster motif built up from three $\left\{\mathrm{Er}_{3} \mathrm{O}_{4}\right\}$

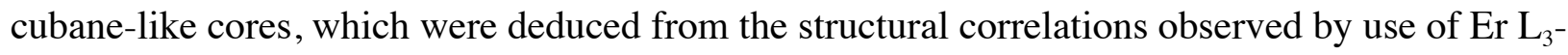
edge electron-yield EXAFS.

\section{ASSOCIATED CONTENT}


Supporting Information. Figures 1-8 showing aspects of X-ray reflectivity and penetration, theoretical phase and amplitude functions (from FEFF), normalized $\mathrm{Er}_{3}$-edge $\mathrm{X}$-ray absorption spectra of the $1 \mathrm{M} \mathrm{ErCl}_{3}$ aqueous electrolyte and the $\mathrm{Er}_{2} \mathrm{O}_{3}$ and $\mathrm{ErCl}_{3} \cdot 6 \mathrm{H}_{2} \mathrm{O}$ solids, including XANES and second differential XANES, EXAFS and FT data with fits, Tables 1 and 2 with the metrical results obtained from two- and three-shell curve fitting of the electron-yield EXAFS data obtained for the electrolyte-He interface at grazing incidence under conditions of total external reflection. This material is available free of charge via the Internet at http://pubs.acs.org.

\section{AUTHOR INFORMATION}

\section{Corresponding Authors}

E-mail: mantonio@anl.gov,1s@anl.gov,schloss@uic.edu

\section{Present Addresses}

${ }^{\text {} B S R F}$, Institute of High Energy Physics, Chinese Academy of Sciences, Beijing 100049, China.

\section{Author Contributions}

The manuscript was written through contributions of all authors. All authors have given approval to the final version of the manuscript.

\section{Funding Sources}

This work is funded by U. S. Department of Energy, Office of Science, Office of Basic Energy Sciences, Division of Chemical Sciences, Biosciences and Geosciences, under contract No DEAC02-06CH11357.

\section{ACKNOWLEDGMENT}


This work and the use of the Advanced Photon Source are supported by the U. S. Department of Energy, Office of Science, Office of Basic Energy Sciences, Division of Chemical Sciences, Biosciences and Geosciences, under contract No DE-AC02-06CH11357.

\section{ABBREVIATIONS}

GI, grazing incidence; XAS, X-ray absorption spectroscopy; EXAFS, extended X-ray absorption fine structure; XAFS, X-ray absorption fine structure; XANES, X-ray absorption near edge structure; TEY, total electron yield; SX, solvent extraction; HEXS, high energy X-ray scattering; FT, Fourier transform; CN, coordination number; TRTCY, total reflection total conversion yield.

\section{REFERENCES}

1. Barthel, J. M. G.; Krienke, H.; Kunz, W., Physical Chemistry of Electrolyte Solutions: Modern Aspects. Springer: New York, 1998; p 401.

2. Enderby, J. E.; Neilson, G. W., The Structure of Electrolyte-Solutions. Rep. Prog. Phys. 1981, $44(6), 593-653$.

3. Durand-Vidal, S.; Simonin, J. P.; Turq, P., Electrolytes at Interfaces. Springer: 2000.

4. Levin, Y.; Dos Santos, A. P.; Diehl, A., Ions at the Air-Water Interface: An End to a Hundred-Year-Old Mystery? Phys. Rev. Lett. 2009, 103 (25).

5. Jungwirth, P.; Tobias, D. J., Ions at the Air/Water Interface. J. Phys. Chem. B 2002, 106 (25), 6361-6373.

6. Manciu, M.; Ruckenstein, E., Ions at the Air/Water Interface. J. Colloid Interface Sci. 2006, $304(2), 541-544$. 
7. Mucha, M.; Frigato, T.; Levering, L. M.; Allen, H. C.; Tobias, D. J.; Dang, L. X.; Jungwirth, P., Unified Molecular Picture of the Surfaces of Aqueous Acid, Base, and Salt Solutions. J. Phys. Chem. B 2005, 109 (16), 7617-7623.

8. Noah-Vanhoucke, J.; Geissler, P. L., On the Fluctuations that Drive Small Ions Toward, and Away from, Interfaces between Polar Liquids and their Vapors. Proc. Natl. Acad. Sci. U. S. A. 2009, 106 (36), 15125-15130.

9. Otten, D. E.; Shaffer, P. R.; Geissler, P. L.; Saykally, R. J., Elucidating the Mechanism of Selective Ion Adsorption to the Liquid Water Surface. Proc. Natl. Acad. Sci. U. S. A. 2012, 109 (3), 701-705.

10. Padmanabhan, V.; Daillant, J.; Belloni, L.; Mora, S.; Alba, M.; Konovalov, O., Specific Ion Adsorption and Short-Range Interactions at the Air Aqueous Solution Interface. Phys. Rev. Lett. 2007, 99 (8), 086105.

11. Petersen, P. B.; Saykally, R. J., Confirmation of Enhanced Anion Concentration at the Liquid Water Surface. Chem. Phys. Lett. 2004, 397 (1-3), 51-55.

12. Petersen, P. B.; Saykally, R. J., On the Nature of Ions at the Liquid Water Surface. Annu. Rev. Phys. Chem. 2006, 57, 333-364.

13. Merkling, P. J.; Munoz-Paez, A.; Marcos, E. S., Exploring the Capabilities of X-Ray Absorption Spectroscopy for Determining the Structure of Electrolyte Solutions: Computed Spectra for $\mathrm{Cr}^{3+}$ or $\mathrm{Rh}^{3+}$ in Water Based on Molecular Dynamics. J. Am. Chem. Soc. 2002, 124 (36), 10911-10920. 
14. Wasse, J. C.; Hayama, S.; Skipper, N. T.; Morrison, D.; Bowron, D. T., Liquid-Liquid Phase Separation and Microscopic Structure in Rubidium-Ammonia Solutions Observed Using X-Ray Absorption Spectroscopy. J.Phys. Chem. B 2003, 107 (51), 14452-14456.

15. Yamaguchi, T., Diffraction and X-Ray Absorption Studies of Electrolyte-Solutions. Pure Appl.Chem. 1990, 62 (12), 2251-2258.

16. Bertagnolli, H.; Ertel, T. S., X-Ray-Absorption Spectroscopy of Amorphous Solids, Liquids, and Catalytic and Biochemical Systems - Capabilities and Limitations. Angew. Chem., Int. Edit. Engl. 1994, 33 (1), 45-66.

17. Filipponi, A., EXAFS for Liquids. J. Phys. Condes. Matter 2001, 13 (7), R23-R60.

18. Lee, P. A.; Citrin, P. H.; Eisenberger, P.; Kincaid, B. M., Extended X-Ray Absorption Fine-Structure - Its Strengths and Limitations as a Structural Tool. Rev. Mod. Phys. 1981, 53 (4), 769-806.

19. Egami, T.; Billinge, S. J. L., Underneath the Bragg Peaks: Structural Analysis of Complex Materials. Pergammon: Amsterdam, 2003.

20. Skanthakumar, S.; Antonio, M. R.; Wilson, R. E.; Soderholm, L., The Curium Aqua Ion. Inorg. Chem. 2007, 46 (9), 3485-3491.

21. Skanthakumar, S.; Soderholm, L., Studying Actinide Correlations in Solution Using High Energy X-ray Scattering. Mater. Res. Soc. Symp. Proc. 2006, 893 (Actinides 2005--Basic Science, Applications and Technology), 411-416. 
22. Soderholm, L.; Skanthakumar, S.; Neuefeind, J., Determination of Actinide Speciation in Solution using High-Energy X-Ray Scattering. Anal. Bioanal. Chem. 2005, 383 (1), 48-55.

23. Moyer, B. A., Ion Exchange and Solvent Extraction: A Series of Advances. CRC Press: Boca Raton, 2012; Vol. 19, p 659.

24. Weaver, B.; Kappelmann, F. A.; Topp, A. C., Quantity Separation of Rare Earths by Liquid-Liquid Extraction. I. The First Kilogram of Gadolinium Oxide. J. Am. Chem. Soc. 1953, $75,3943-5$.

25. Gschneidner, K. A., Jr ; Eyring, L., Handbook on the Physics and Chemistry of Rare Earths. The Role of Rare Earths in Catalysis. Elsevier: New York, 2000; Vol. 29, p 419.

26. Gschneidner, K. A., Jr ; Eyring, L.; Maple, M. B., Handbook on the Physics and Chemistry of Rare Earths. High-Temperature Superconductors - I. Elsevier: New York, 2000; Vol. 30, p 637.

27. Gschneidner, K. A., Jr ; Eyring, L.; Maple, M. B., Handbook on the Physics and Chemistry of Rare Earths. High-Temperature Superconductors - II. Elsevier: New York, 2001; Vol. 31, p 687.

28. Sorace, L.; Benelli, C.; Gatteschi, D., Lanthanides in Molecular Magnetism: Old Tools in a New Field. Chem. Soc. Rev. 2011, 40 (6), 3092-3104.

29. Rocha, J.; Carlos, L. D.; Paz, F. a. A.; Ananias, D., Luminescent Multifunctional Lanthanides-Based Metal-Organic Frameworks. Chem. Soc. Rev. 2011, 40 (2), 926-940. 
30. Soderholm, L.; Skanthakumar, S.; Wilson, R. E., Structures and Energetics of Erbium Chloride Complexes in Aqueous Solution. J. Phys. Chem. A 2009, 113 (22), 6391-6397.

31. Habenschuss, A.; Spedding, F. H., The Coordination (Hydration) of Rare Earth Ions in Aqueous Chloride Solutions from X-ray Diffraction. I. $\mathrm{TbCl}_{3}, \mathrm{DyCl}_{3}, \mathrm{ErCl}_{3}, \mathrm{TmCl}_{3}$, and $\mathrm{LuCl}_{3} . J$. Chem. Phys. 1979, 70 (6), 2797-2806.

32. Fernandez-Ramirez, E.; Jimenez-Reyes, M.; Solache-Rios, J., Effects of Ionic Strength and Charge Density on the Stability of Chloride Complexes of Trivalent Lanthanides. J. Chem. Eng. Data 2008, 53, 1756-1761.

33. Smirnov, P. R.; Grechin, O. V., Coordination of Ions in Aqueous Solutions of Erbium Chloride from X-ray diffraction Data. Russ J Coord Chem+ 2013, 39 (9), 685-688.

34. Bu, W.; Hou, B.; Mihaylov, M.; Kuzmenko, I.; Lin, B.; Meron, M.; Soderholm, L.; Luo, G.; Schlossman, M. L., X-ray Fluorescence from a Model Liquid/Liquid Solvent Extraction System. J. Appl. Phys. 2011, 110, 102214, 1-6.

35. Luo, G.; Bu, W.; Mihaylov, M.; Kuzmenko, I.; Schlossman, M. L.; Soderholm, L., X-ray Reflectivity Reveals a Nonmonotonic Ion-Density Profile Perpendicular to the Surface of $\mathrm{ErCl}_{3}$ Aqueous Solutions. J. Phys. Chem. C 2013, 117, DOI: 10.1021/jp4067247.

36. Edwards, S. A.; Williams, D. R. M., Surface Tension of Electrolyte Solutions: Comparing the Effects of Ionic Dispersion Forces and Solvation. Europhys. Lett. 2006, 74 (5), 854-860.

37. Levin, Y.; Flores-Mena, J. R., Surface Tension of Strong Electrolytes. Europhys. Lett. 2001, 56 (2), 187-192. 
38. Manciu, M.; Ruckenstein, E., Specific Ion Effects via Ion Hydration: I. Surface Tension. Adv. Colloid Interface Sci. 2003, 105, 63-101.

39. Markin, V. S.; Volkov, A. G., Quantitative Theory of Surface Tension and Surface Potential of Aqueous Solutions of Electrolytes. J. Phys. Chem. B 2002, 106 (45), 11810-11817.

40. Ninham, B. W.; Yaminsky, V., Ion Binding and Ion Specificity: The Hofmeister Effect and Onsager and Lifshitz Theories. Langmuir 1997, 13 (7), 2097-2108.

41. Ruckenstein, E.; Manciu, M., Specific Ion Effects via Ion Hydration: II. Double Layer Interaction. Adv. Colloid Interface Sci. 2003, 105, 177-200.

42. Yang, L. J.; Fan, Y. B.; Gao, Y. Q., Differences of Cations and Anions: Their Hydration, Surface Adsorption, and Impact on Water Dynamics. J. Phys. Chem. B 2011, 115 (43), 1245612465.

43. Ishiguro, S.; Umebayashi, Y.; Komiya, M., Thermodynamic and Structural Aspects on the Solvation Steric Efffect of Lanthanide(III) - Dependence on the Ionic Size. Coord. Chem. Rev. 2002, 226, 103-111.

44. Jones, D. J.; Roziere, J.; Olivera-Pastor, P.; Rodriguez-Castellon, E.; Jimenez-Lopez, A., Local Environment of Intercalated Lanthanide Ions in Vermiculite. J. Chem. Soc.-Faraday Trans. 1991, 87 (18), 3077-3081.

45. Persson, I.; D'angelo, P.; De Panfilis, S.; Sandstrom, M.; Eriksson, L., Hydration of Lanthanoid(III) Ions in Aqueous Solution and Crystalline Hydrates Studied by EXAFS Spectroscopy and Crystallography: The Myth of the "Gadolinium Break". Chem. Eur. J. 2008, 14 (10), 3056-3066. 
46. Yaita, T.; Narita, H.; Suzuki, S.; Tachimori, S.; Motohashi, H.; Shiwaku, H., Structural Study of Lanthanides(III) in Aqueous Nitrate and Chloride Solutions by EXAFS. J. Radioanal. Nucl. Chem. 1999, 239 (2), 371-375.

47. Beudert, R.; Bertagnolli, H.; Zeller, M., Ion-Ion And Ion-Water Interactions in an Aqueous Solution of Erbium Bromide $\left(\mathrm{ErBr}_{3}\right)$. A Differential Anomalous X-Ray Scattering Study. J. Chem. Phys. 1997, 106 (21), 8841-8848.

48. Johansson, G.; Yokoyama, H., Inner-Sphere and Outer-Sphere Complex-Formation in Aqueous Erbium Halide and Perchlorate Solutions - An X-Ray-Diffraction Study Using Isostructural Substitution. Inorg. Chem. 1990, 29 (13), 2460-2466.

49. Beno, M. A.; Engbretson, M.; Jennings, G.; Knapp, G. S.; Linton, J.; Kurtz, C.; Rütt, U.; Montano, P. A., BESSRC-CAT Bending Magnet Beamline at the Advanced Photon Source. Nucl. Instrum. Methods Phys. Res. A 2001, 467-468, 699-702.

50. Krause, M. O.; Oliver, J. H., Natural Widths of Atomic K and L levels, K $\alpha$ X-ray Lines and Several KLL Auger Lines. J. Phys. Chem. Ref. Data 1979, 8 (2), 329-338.

51. Exafs Materials. http://exafsmaterials.com/index.html. (Access date: 8 May 2015)

52. Nagatani, H.; Tanida, H.; Ozeki, T.; Watanabe, I., Zinc(II) Porphyrins at the Air-Water Interface as Studied by Polarized Total-Reflection X-Ray Absorption Fine Structure. Langmuir 2006, 22 (1), 209-212.

53. Nagatani, H.; Tanida, H.; Watanabe, I.; Sagara, T., Extended X-ray Absorption Fine Structure of Copper(II) Complexes at the Air-Water Interface by a Polarized Total-Reflection Xray Absorption Technique. Anal. Sci. 2009, 25 (4), 475-480. 
54. Ruggles, J. L.; Foran, G. J.; Tanida, H.; Nagatani, H.; Jimura, Y.; Watanabe, I.; Gentle, I. R., Interfacial Behavior of Tetrapyridylporphyrin Monolayer Arrays. Langmuir 2006, 22 (2), 681-686.

55. Tanida, H.; Nagatani, H.; Watanabe, I., Polarized Total-Reflection X-Ray Absorption Fine Structure for Self-Assembled Monolayer of Zinc Porphyrin at Air-Water Interface. J. Chem. Phys. 2003, 118 (23), 10369-10371.

56. Watanabe, I.; Tanida, H., Total-Reflection Method Applied to an X-Ray-Absorption Fine-Structure Study of Aqueous-Solution Surface. Anal. Sci. 1995, 11 (3), 525-528.

57. Watanabe, I., EXAFS of Bromide Ion in Solvents and at Air/Solution Interface. J. Mol. Liq. 1995, 65-6, 245-252.

58. Song, I. H.; Rickett, B.; Janavicius, P.; Payer, J. H.; Antonio, M. R., In-Situ TotalElectron-Yield Sulfur K-Edge XAFS Measurements During Exposure of Copper to an $\mathrm{SO}_{2}$ Containing Humid Atmosphere. Nucl. Instrum. Methods Phys. Res. Sect. A-Accel. Spectrom. Dect. Assoc. Equip. 1995, 360 (3), 634-641.

59. Elam, W. T.; Kirkland, J. P.; Neiser, R. A.; Wolf, P. D., Depth Dependence for Extended X-Ray-Absorption Fine-Structure Spectroscopy Detected via Electron Yield in $\mathrm{He}$ and in Vacuum. Phys. Rev. B 1988, 38 (1), 26-30.

60. Girardeau, T.; Mimault, J.; Jaouen, M.; Chartier, P.; Tourillon, G., Sampling Depth in Conversion-Electron Detection Used for X-Ray Absorption. Phys. Rev. B 1992, 46 (11), 71447152. 
61. Kordesch, M. E.; Hoffman, R. W., Electron-Yield Extended X-Ray Absorption FineStructure with the Use of a Gas-Flow Electron Detector. Phys. Rev. B 1984, 29 (1), 491-492.

62. Tourillon, G.; Dartyge, E.; Fontaine, A.; Lemonnier, M.; Bartol, F., Electron Yield XRay Absorption-Spectroscopy at Atmospheric-Pressure. Phys. Lett. A 1987, 121 (5), 251-257.

63. Mroczkowski, S.; Lichtman, D., Calculated Auger Yields and Sensitivity Factors for KLL-NOO Transitions with 1-10 kV Primary Beams. J Vac Sci Technol A 1985, 3 (4), 18601865.

64. Hayakawa, S.; Tanaka, A.; Hirokawa, T., Contribution of Ni KLL Auger Electrons to the Probing Depth of the Conversion Electron Yield Measurements. Anal. Sci. 2010, 26 (2), 233237.

65. Ressler, T., WinXAS: A Program for X-Ray Absorption Spectroscopy Data Analysis under MS-Windows. J. Synchrotron Radiat. 1998, 5 (2), 118-122.

66. Rehr, J. J.; Albers, R. C., Theoretical Approaches to X-Ray Absorption Fine Structure. Rev. Mod. Phys. 2000, 72 (3), 621-654.

67. Stern, E. A., Number of Relevant Independent Points in X-Ray-Absorption FineStructure Spectra. Phys. Rev. B 1993, 48 (13), 9825-9827.

68. Downward, L.; Booth, C. H.; Lukens, W. W.; Bridges, F., A Variation of the F-Test for Determining Statistical Relevance of Particular Parameters in EXAFS Fits. In X-Ray Absorption Fine Structure-XAFS13, Hedman, B.; Painetta, P., Eds. 2007; Vol. 882, pp 129-131. 
69. Antonio, M. R.; Soderholm, L.; Ellison, A. J. G., Local Environments of Erbium and Lutetium in Sodium Silicate Glasses. J. Alloys Compd. 1997, 250 (1-2), 536-540.

70. Staub, U.; Antonio, M. R.; Soderholm, L.; Guillaume, M.; Henggeler, W.; Furrer, A., Tb Oxidation-State and Hybridization in $\mathrm{Y}_{0.9} \mathrm{~Tb}_{0.1} \mathrm{Ba}_{2} \mathrm{Cu}_{3} \mathrm{O}_{7-\delta}(\delta=0.02,0.84)$ - A MagneticSusceptibility and X-Ray-Absorption Study. Phys. Rev. B 1994, 50 (10), 7085-7091.

71. Bu, W.; Yu, H.; Luo, G. M.; Bera, M. K.; Hou, B. Y.; Schuman, A. W.; Lin, B. H.; Meron, M.; Kuzmenko, I.; Antonio, M. R., et al., Observation of a Rare Earth Ion-Extractant Complex Arrested at the Oil Water Interface During Solvent Extraction. J. Phys. Chem. B 2014, $118(36), 10662-10674$.

72. Graeber, E. J.; Conrad, G. H.; Duliere, S. F., Crystallographic Data for Solvated Rare Earth Chlorides. Acta Cryst. 1966, 21 (6), 1012-1013.

73. Karbowiak, M.; Gnutek, P.; Rudowicz, C., Reanalysis of Energy Levels and Crystal Field Parameters for $\mathrm{Er}^{3+}$ and $\mathrm{Tm}^{3+}$ Ions at C-2 Symmetry Sites in Hexahydrated Trichloride CrystalsIntricate Aspects of Multiple Solutions for Monoclinic Symmetry. Physica B 2010, 405 (7), 1927-1940.

74. Rogers, R. D.; Kurihara, L. K., Crystal Structures of Dichlorohexaaquayttrium(III) Chloride, and Dichlorohexaaquaerbium(III) Chloride Lanthanide Actinide Res. 1986, 1, 296-306.

75. Mao, Y. B.; Bargar, J.; Toney, M.; Chang, J. P., Correlation Between Luminescent Properties and Local Coordination Environment for Erbium Dopant in Yttrium Oxide Nanotubes. J. Appl. Phys. 2008, 103 (9). 
76. Saiki, A.; Ishizawa, N.; Mizutani, N.; Kato, M., Structural Change of C-Rare Earth Sesquioxides Yb2O3 and Er2O3 as a Function of Temperature. J. Ceramic Assoc., Jpn. 1985, 93 (1082), 649-654.

77. Although the effects of hydrogen on XANES data can be significant,76,77 the effects of hydrogen backscattering in EXAFS data are known to be miniscule.78 Distant Er-H correlations would be difficult, if not impossible to resolve by use of Er $\mathrm{L}_{3}$-edge EXAFS.

78. Benfatto, M.; Solera, J. A.; Chaboy, J.; Proietti, M. G.; Garcia, J., Theoretical Analysis of X-Ray Absorption Near-Edge Structure of Transition-Metal Aqueous Complexes in Solution at the Metal K Edge. Phys. Rev. B 1997, 56 (5), 2447-2452.

79. Tanida, H.; Kato, K.; Watanabe, I., Hydrogen Atom Position in Hydrated Iodide Anion from X-Ray Absorption Near Edge Sructure. Bull. Chem. Soc. Jpn. 2003, 76 (9), 1735-1740.

80. Wilson, K. R.; Tobin, J. G.; Ankudinov, A. L.; Rehr, J. J.; Saykally, R. J., Extended Xray Absorption Fine Structure from Hydrogen Atoms in Water. Phys. Rev. Lett. 2000, 85 (20), 4289-4292.

81. Lundberg, D.; Persson, I.; Eriksson, L.; D'angelo, P.; De Panfilis, S., Structural Study of the N,N '-Dimethylpropyleneurea Solvated Lanthanoid (III) Ions in Solution and Solid State with an Analysis of the Ionic Radii of Lanthanoid(III) Ions. Inorg. Chem. 2010, 49 (10), 4420-4432.

82. Hudson, E. A.; Allen, P. G.; Terminello, L. J.; Denecke, M. A.; Reich, T., Polarized XRay-Absorption Spectroscopy of the Uranyl Ion: Comparison of Experiment and Theory. Phys. Rev. B 1996, 54 (1), 156-165. 
83. Kashimoto, K.; Shibata, K.; Matsuda, T.; Hoshide, M.; Jimura, Y.; Watanabe, I.; Tanida, H.; Matsubara, H.; Takiue, T.; Aratono, M., Preferential Adsorption of Cationic Surfactant Mixture Studied by Bromide Ion Selective Total-Reflection XAFS Measurement. Langmuir 2008, 24 (13), 6693-6697.

84. Kashimoto, K.; Takata, Y.; Matsuda, T.; Ikeda, N.; Matsubara, H.; Takiue, T.; Aratono, M.; Tanida, H.; Watanabe, I., Study on the Surface Density of Surface-Active Substances through Total-Reflection X-Ray Absorption Fine Structure Measurement. Langmuir 2006, 22 (20), 8403-8408.

85. Shimamoto, K.; Onohara, A.; Takumi, H.; Watanabe, I.; Tanida, H.; Matsubara, H.; Takiue, T.; Aratono, M., Miscibility and Distribution of Counterions of Imidazolium Ionic Liquid Mixtures at the Air/Water Surface. Langmuir 2009, 25 (17), 9954-9959.

86. Watanabe, I.; Tanida, H.; Kawauchi, S., Coordination Structure of Zinc (II) Ions on a Langmuir Monolayer, Observed by Total-Reflection X-Ray Absorption Fine Structure. J. Am. Chem. Soc. 1997, 119 (49), 12018-12019.

87. Watanabe, I.; Tanida, H.; Kawauchi, S.; Harada, M.; Nomura, M., X-Ray Absorption Spectroscopy of Liquid Surface. Rev. Sci. Instrum. 1997, 68 (9), 3307-3311.

88. Knope, K. E.; Soderholm, L., Solution and Solid-State Structural Chemistry of Actinide Hydrates and their Hydrolysis and Condensation Products. Chem. Rev. 2013, 113 (2), 944-994.

89. Jordan, D. S.; Saslow, S. A.; Geiger, F. M., Exponential Sensitivity and Speciation of Al(III), Sc(III), Y(III), La(III), and Gd(III) at Fused Silica/Water Interfaces. J. Phys. Chem. A 2011, 115 (50), 14438-14445. 
90. Abascal, J. L. F.; Turq, P., Cluster Structure in Model Electrolyte-Solutions. Chem. Phys. 1991, 153 (1-2), 79-89.

91. Bresme, F.; Abascal, J. L. F., Pair Connectedness Functions and Percolation in HighlyCharged Electrolyte-Solutions. J. Chem. Phys. 1993, 99 (11), 9037-9046.

92. Montoro, J. C. G.; Bresme, F.; Abascal, J. L. F., Ionic Association in ElectrolyteSolutions - A Voronoi Polyhedra Analysis. J. Chem. Phys. 1994, 101 (12), 10892-10898.

93. Andrews, P. C.; Gee, W. J.; Junk, P. C.; Maclellan, J. G., Systematic Study of The Formation of the Lanthanoid Cubane Cluster Motif Mediated by Steric Modification of Diketonate Ligands. Dalton Trans. 2011, 40 (45), 12169-12179.

94. Cheng, J.-W.; Zhang, J.; Zheng, S.-T.; Zhang, M.-B.; Yang, G.-Y., LanthanideTransition-Metal Sandwich Framework Comprising $\left\{\mathrm{Cu}_{3}\right\}$ Cluster Pillars and Layered Networks of $\left\{\mathrm{Er}_{36}\right\}$ Wheels. Angew. Chem. Int. Ed. 2006, 45 (1), 73-77.

95. Wang, R.; Liu, H.; Carducci, M. D.; Jin, T.; Zheng, C.; Zheng, Z., Lanthanide Coordination with $\alpha$-Amino Acids under Near Physiological pH Conditions: Polymetallic Complexes Containing the Cubane-Like $\left[\operatorname{Ln}_{4}\left(\mu_{3}-\mathrm{OH}\right)_{4}\right]^{8+}$ Cluster Core. Inorg. Chem. 2001, 40 (12), 2743-2750.

96. Wang, Z. L.; Fang, W. H.; Yang, G. Y., A Series of 1-D Lanthanide Coordination Polymers Based on $\left[\mathrm{Ln}_{4}\left(\mu_{3}-\mathrm{OH}\right)_{4}\right](\mathrm{Ln}=\mathrm{Er}, \mathrm{Tb}, \mathrm{Gd})$ Cluster Units. J. Clust. Sci. 2009, 20 (4), $725-733$. 
97. Zheng, Z., Cluster Compounds of Rare-Earth Elements. In Handbook on the Physics and Chemistry of Rare Earths, Gschneidner, K. A.; Bunzli, J.-C. G.; Pecharsky, V. K., Eds. Elsevier: New York, 2010; Vol. Volume 40, pp 109-239.

98. Ma, B. Q.; Zhang, D. S.; Gao, S.; Jin, T. Z.; Yan, C. H.; Xu, G. X., From Cubane to Supercubane: The Design, Synthesis, and Structure of a Three-Dimensional Open Framework Based on a $\mathrm{Ln}_{4} \mathrm{O}_{4}$ Cluster. Angew. Chem., Int. Edit. 2000, 39 (20), 3644-3646.

99. Giester, G.; Unfried, P.; Zak, Z., Syntheses and Crystal Structures of Some New Rare Earth Basic Nitrates .2. $\mathrm{Ln}_{6} \mathrm{O}(\mathrm{OH})_{8}\left(\mathrm{H}_{2} \mathrm{O}\right)_{12}\left(\mathrm{NO}_{3}\right)_{6}\left(\mathrm{NO}_{3}\right)_{2} \cdot \mathrm{xH}_{2} \mathrm{O}, \mathrm{Ln}=\mathrm{Sm}, \mathrm{Dy}, \mathrm{Er} ; \mathrm{x}(\mathrm{Sm})=6$, $\mathrm{x}(\mathrm{Dy})=5, \mathrm{x}(\mathrm{Er})=4$. J. Alloys Compd. 1997, 257 (1-2), 175-181.

100. Giester, G.; Zak, Z.; Unfried, P., Syntheses and Crystal Structures of Rare Earth Basic Nitrates Hydrates Part III. [ $\left.\mathrm{Ln}_{6}\left(\mu_{6}-\mathrm{O}\right)\left(\mu_{3}-\mathrm{OH}\right)_{8}\left(\mathrm{H}_{2} \mathrm{O}\right)_{12}\left(\eta^{2}-\mathrm{NO}_{3}\right)_{6}\right]\left(\mathrm{NO}_{3}\right)_{2} \cdot \mathrm{xH}_{2} \mathrm{O}, \mathrm{Ln}=\mathrm{Y}, \mathrm{Sm}, \mathrm{Eu}$, Gd, Tb, Dy, Ho, Er, Tm, Yb, Lu; x=3, 4, 5, 6. J. Alloys Compd. 2009, 481 (1-2), 116-128.

101. Kanan, M. W.; Yano, J.; Surendranath, Y.; Dinca, M.; Yachandra, V. K.; Nocera, D. G., Structure and Valency of a Cobalt-Phosphate Water Oxidation Catalyst Determined by In Situ X-ray Spectroscopy. J. Am. Chem. Soc. 2010, 132 (39), 13692-13701.

102. Knope, K. E.; Wilson, R. E.; Skanthakumar, S.; Soderholm, L., Synthesis and Characterization of Thorium(IV) Sulfates. Inorg. Chem. 2011, 50 (17), 8621-8629.

103. Skanthakumar, S.; Antonio, M. R.; Soderholm, L., A Comparison of Neptunyl(V) and Neptunyl(VI) Solution Coordination: The Stability of Cation-Cation Interactions. Inorg. Chem. 2008, $47(11), 4591-4595$. 
104. Soderholm, L.; Skanthakumar, S.; Wilson, R. E., Structural Correspondence between Uranyl Chloride Complexes in Solution and Their Stability Constants. J. Phys. Chem. A 2011, $115(19), 4959-4967$.

105. Wilson, R. E.; Skanthakumar, S.; Cahill, C. L.; Soderholm, L., Structural Studies Coupling X-ray Diffraction and High-Energy X-ray Scattering in the $\mathrm{UO}_{2}{ }^{2+}-\mathrm{HBr}(\mathrm{aq})$ System. Inorg. Chem. 2011, 50 (21), 10748-10754.

106. Wilson, R. E.; Skanthakumar, S.; Sigmon, G.; Burns, P. C.; Soderholm, L., Structures of Dimeric Hydrolysis Products of Thorium. Inorg. Chem. 2007, 46 (7), 2368-2372.

107. Kuzmin, A.; Parent, P., Focusing and Superfocusing Effects in X-Ray-Absorption FineStructure at the Iron $\mathrm{K}$ Edge in $\mathrm{FeF}_{3}$.J. Phys.-Condes. Matter 1994, 6 (23), 4395-4404.

108. Shannon, R. D., Revised Effective Ionic Radii and Systematic Studies of Interatomic Distances in Halides and Chalcogenides. Acta Cryst. 1976, A32, 751-767. 
Insert Table of Contents Graphic and Synopsis Here

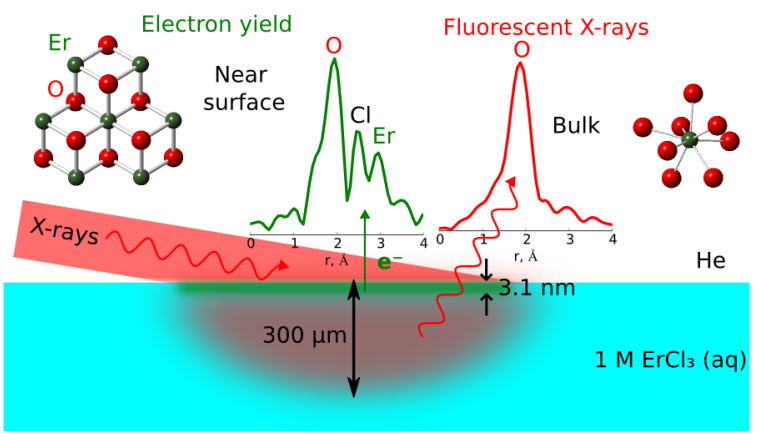

